This is the author's manuscript for publication. The publisher-formatted version may be available through the publisher's web site or your institution's library.

\title{
Dynamic factor analysis of surface water management impacts on soil and bedrock water contents in Southern Florida Lowlands
}

I. Kisekka, K. W. Migliaccio, R. Muñoz-Carpena, B. Schaffer, Y. C. Li

\section{How to cite this manuscript}

If you make reference to this version of the manuscript, use the following information:

Kisekka, I., Migliaccio, K. W., Muñoz-Carpena, R., Schaffer, B., \& Li, Y. C. (2013). Dynamic factor analysis of surface water management impacts on soil and bedrock water contents in Southern Florida Lowlands. Retrieved from http://krex.ksu.edu

\section{Published Version Information}

Citation: Kisekka, I., Migliaccio, K. W., Muñoz-Carpena, R., Schaffer, B., \& Li, Y. C. (2013). Dynamic factor analysis of surface water management impacts on soil and bedrock water contents in Southern Florida Lowlands. Journal of Hydrology, 488, 55-72.

Copyright: (C) 2013 Elsevier B.V.

Digital Object Identifier (DOI): doi:10.1016/j.jhydrol.2013.02.035

Publisher's Link: http://www.sciencedirect.com/science/article/pii/S0022169413001583

This item was retrieved from the K-State Research Exchange (K-REx), the institutional repository of Kansas State University. K-REx is available at http://krex.ksu.edu 
Submitted to journal of Hydrology

\section{Dynamic Factor Analysis of Surface Water Management Impacts on Soil and Bedrock Water}

\section{Contents in Southern Florida Lowlands}

\section{Kisekka ${ }^{a}$, K.W. Migliaccio ${ }^{a}$, R. Muñoz-Carpena ${ }^{\text {, }}$, B. Schaffer ${ }^{a}$, Y.C. Li ${ }^{a}$}

University of Florida, IFAS Tropical Research and Education Center 18905 SW 280 ${ }^{\text {th }}$ St Homestead, FL $33031^{\mathrm{a}}$

University of Florida, Agricultural and Biological Engineering Department, P. O. Box 110570, Gainesville, FL 32611

${ }^{a}$ Corresponding author: Kati W. Migliaccio; Tel.: +1 305-246-7001 x288; fax: +1 305-246-7003. E-mail address: klwhite@ufl.edu.

\section{Abstract}

As part of the C111 spreader canal project, structural and operational modifications involving incremental raises in canal stage are planned along one of the major canals (i.e., C111) separating Everglades National Park and agricultural production areas to the east of the park. This study used Dynamic Factor Analysis (DFA) as an alternative tool to physically based models to explore the relationship between different hydrologic variables and the effect of proposed changes in surface water management on soil and bedrock water contents in south Florida. To achieve the goal, objectives were to: (1) use DFA to identify the most important factors affecting temporal variation in soil and bedrock water contents, (2) develop a simplified DFA based regression model for predicting soil and bedrock water contents as a function of canal stage and (3) assess the effect of the proposed incremental raises in canal stage on soil and bedrock water contents. DFA revealed that 5 common trends were the minimum required to describe unexplained variation in the 11 time series studied. Introducing canal stage, water table evaporation and net recharge resulted in lower Akaike information criterion (AIC) and higher Nash-Sutcliffe $\left(\mathrm{C}_{\mathrm{eff}}\right)$ values. Results indicated that canal stage significantly $(\mathrm{t}>2)$ drives temporal variation in soil and bedrock water contents, which was represented as scaled frequency while net surface recharge was significant in 7 out of the 11 time series analyzed. The effect of water table evaporation was not significant at all sites. Results also indicated that the most important factor influencing temporal variation in soil and bedrock water 
27 contents in terms of regression coefficient magnitude was canal stage. Based on DFA results, a simple

28 regression model was developed to predict soil and bedrock water contents at various elevations as a

29 function of canal stage and net recharge. The performance of the simple model ranged from good $\left(\mathrm{C}_{\text {eff }}\right.$

30 ranging from 0.56 to 0.74$)$ to poor $\left(\mathrm{C}_{\mathrm{ef} f}\right.$ ranging from 0.10 to 0.15$)$, performance was better at sites with

31 smaller depths to water table $(<1 \mathrm{~m})$ highlighting the effect of micro-topography on soil and bedrock

32 water content dynamics. Assessment of the effect of 6,9 and $12 \mathrm{~cm}$ increases in canal stage using the

33 simple regression model indicated that changes in temporal variation in soil and bedrock water contents

34 were negligible (average $<1.0 \%$ average change) at 500 to $2000 \mathrm{~m}$ from C111 (or low elevations) which

35 may be attributed to the near saturation conditions already occurring at these sites. This study used DFA

36 to explore the relationship between soil and bedrock water dynamics and surface water stage in shallow

37 water table environments. This approach can be applied to any system in which detailed physical

38 modeling would be limited by inadequate information on parameters or processes governing the physical

39 system.

40 Key words: Soil water content, bedrock water content, scaled frequency, Dynamic Factor Analysis, canal

41 stage, water table

42 Abbreviations: DFA, dynamic factor analysis; SF, scaled frequency; $\mathrm{R}_{\text {net }}$, net surface recharge; MWT, 43 mean water table elevation; S177T, C111 canal stage; SFWMD, South Florida Water Management 44 District; AIC, Akaike information criterion; BIC, Bayesian information criterio; VIF, variance inflation 45 factor; NGVD29, National Geodetic Vertical Datum of 1929. 
47

\section{Introduction}

In an attempt to correct some of the undesired consequences of south Florida's extensive drainage canal network on the region's ecosystem, an environmental restoration project named the Comprehensive Everglades Restoration Plan (CERP) is currently under implementation. CERP was approved by the United States Congress under the Water Resources Development Act (2000). One of the 68 components that comprise CERP is the $\mathrm{C} 111$ spreader canal project whose goal is to reduce the impacts of $\mathrm{C} 111$ (i.e., reduce groundwater seepage into C111) on Everglades National Park (ENP) and Taylor Slough which is a natural drainage feature that conveys water to Florida while maintaining existing levels of flood protection in the adjacent agricultural and urban areas (U.S. Army Corps of Engineers [USACP] and South Florida Water Management District [SFWMD], 2009). As part of the C111 spreader canal project, structural modifications and operational adjustments involving incremental raises in canal stage are planned along one of the major canals (i.e., C111) separating ENP and agricultural production areas to the east of the canal. The increase in canal stage will occur by changing surface water management at the gated spillway located at structure named S18C (Fig. 1) in the form of incremental raises in canal stage of up to $12 \mathrm{~cm}$.

It is anticipated that the planned rise in C111 canal stage will affect water table levels in the adjacent agricultural areas. Earlier research indicated that there is substantial interaction between the highly permeable Biscayne aquifer and water level in canals (Genereux and Slater, 1999). The hydraulic connection between Biscayne aquifer and canal C111 causes the shallow water table system to fluctuate with respect to changes in canal stage. Using the drain to equilibrium assumption, Barquin et al. (2011) showed that water table elevation in the Biscayne aquifer significantly influenced soil and bedrock water contents in a fruit orchard with soil and bedrock formations that are very similar to our current study site.

Therefore, raising water table elevation could result in increased soil and bedrock water contents or greater saturation of the root zone which could affect the production of winter vegetables predominately grown in this area. Saturation of the root zone could impact yield potential by impairing root growth due 
72 to anoxia, reducing stomatal conductance, and reducing net $\mathrm{CO}_{2}$ assimilation (Schaffer, 1998). In addition

73 to physiological stress, having the soils saturated could render movement of machinery difficult and also

74 impact growing season and market dates. However, it is not known to what extent the proposed structural

75 modifications and operational adjustments along canal C111 would impact water table elevations and thus

76 soil and bedrock water contents in agricultural areas east of the canal.

77 Vegetable production in Miami-Dade County, a substantial proportion of which is located along the 78 extensive eastern boundary of ENP, is a significant contributor to both the local and state economies.

79 According to the 2007 Census of Agriculture from the US Department of Agriculture (USDA, 2007), the

80 total value of vegetables produced in Miami-Dade County was over 128 million dollars in 2007. Green

81 beans, sweet corn, squash, tomatoes and sweet potato are the dominant vegetables grown in the area.

82 There is need to quantify the impacts of hydrological modifications and surface water management on

83 agricultural land use at field scale because large regional hydrology models have discretization that might

84 not be suitable for resolving small scale micro-topographic differences within the landscape.

Long term monitoring and exploratory analysis of soil and limestone bedrock water contents could characterize the effect of various drivers on the temporal variability of water contents. The soils in the

87 agricultural areas east of $\mathrm{C} 111$ were created from scarification of the underlying limestone bedrock hence

88 they are very shallow and have high gravel content. Three main stresses that influence soil water content

89 that could be included in exploratory analysis are 1) canal stage, which affects water table elevation; 2)

90 rainfall, and 3) evapotranspiration. While these stresses may be assessed using physically based models of 91 vadose zone flow and transport, implementation of unsaturated flow models (e.g., WAVE [Vanclooster

92 et al., 1995] or HYDRUS [Šimůnek, et al., 2008]) is not an easy task since they contain numerous

93 parameters and processes that have to be quantified (Ritter et al., 2009). In very gravelly and shallow soils

94 such as those in south Miami-Dade County, quantifying parameters such as hydraulic conductivity for use

95 in Richards' equation is further complicated by having porous gravely soils that are not homogeneous.

96 Previous applications of WAVE, for example, in gravely soils of south Florida have indicated that a 
detailed description of soil hydraulic properties (e.g., using dual porosity) could result in improved robustness of vadose zone models (Duwig et al., 2003; Muñoz-Carpena et al., 2008). Therefore the success of applying physically based models to simulate soil and bedrock water dynamics depends largely on proper conceptualization of location specific processes and proper measurement or estimation of parameters. In this context, complementary exploratory tools such as Dynamic Factor Analysis (DFA) which are not processes based are desired as simpler preliminary exploratory tools that could also be used for preliminary predictions of the impact of surface water management decisions on land use.

A comprehensive description of DFA and modeling can be found in Zuur et al. (2003). For purposes of aiding discussion, we only provide a brief description of this technique. DFA is a dimension reduction multivariate time series analysis technique that is used to estimate underlying common patterns (common trends) in short time series as well as the effect of explanatory variables on response variables. The advantage of DFA over other traditional dimensional reduction techniques (e.g., Factor Analysis or Principal Component Analysis) is that DFA accounts for the time component. This allows the underlying hidden effects driving the temporal variation in the observed time series data to be detected (Zuur et al., 2003). DFA does not require observed time series to be long and stationary. Although non-stationarity could be handled through de-trending, trends in the times series could hold necessary information required to explain the temporal dynamics in the observed variable (Ritter et al., 2009). In addition, DFA can handle missing values in the observed time series (i.e., DFA does not require data sets to be regularly spaced). Missing values in observed time series data sets are not uncommon especially when time series data are obtained from unattended automatic data logging field instruments (e.g., multi-sensor capacitance probes for soil water monitoring).

DFA applications are documented in literature from several disciplines (e.g., Geweke, 1977; Márkus et al., 1999; Zou and Yu, 1999; Zuur et al., 2003; Zuur and Pierce, 2004; Muñoz-Carpena et al., 2005; Ritter and Muñoz-Carpena, 2006; Zuur et al., 2007; Ritter et al., 2009; Kaplan et al., 2010a; Kaplan and Muñoz-Carpena, 2011). Thus, we only provide a brief review of the most relevant examples. Ritter and 
122 Muñoz-Carpena (2006) applied DFA and modeling to study interactions between surface water and

123 groundwater levels within the Frog Pond agricultural area located west of canal C111 in south Florida

124 (Fig.1). Their results indicated that the two canals surrounding the Frog Pond area had the greatest

125 influence on temporal changes in water table elevation. Their study did not address the issue of the impact

126 of surface management decisions on soil water content. Soil water is a major concern for vegetable

127 growers in south Florida due to the impact saturated or near saturated soil conditions have on planting

128 dates and yield losses (Fig. 1).

Others have applied DFA and modeling to study soil water dynamics. Ritter et al. (2009) applied DFA to analyze temporal changes in soil water status of a humid, subtropical, evergreen forest in Canary Islands, Spain. Kaplan and Muñoz-Carpena (2011) applied DFA to study the complementary effects of

132 surface and groundwater on soil water dynamics in a coastal flood plain. Thus, DFA was successfully 133 used to identify unexplained variability in observed hydrologic time series and to assess the effect of 134 selected explanatory variables on response variables (observed time series of interest).

The difference between our study and prior studies is that we applied DFA to investigate the effect of surface water management in canals on soil water dynamics in an agricultural area with very shallow very 137 gravely loam soils, and unlike in the previous studies we also considered not only the effects of potential 138 evaporation $\left(\mathrm{ET}_{\mathrm{o}}\right)$ but also the effect of water table evaporation given the shallow water table. We then 139 attempted to develop a simple model, using information from the DFA, to predict soil water content from 140 easily measured variables such as canal stage and recharge (i.e., difference between rainfall and 141 evapotranspiration). Canal stage was selected instead of water table elevation since water table elevation 142 data in our study area are less complete due to the limited period of record and the limited number of 143 continuously monitored groundwater wells. Canal stage has been monitored for a longer period of record 144 and has no foreseeable end of data collection, thus it is a more reliable measurement for long-term use.

145 We assumed that at any given time, water table elevation is approximately equal to canal stage. We 146 concede that at certain times this assumption might not hold e.g., immediately after or during storm 
Submitted to journal of Hydrology

147

148

149

150

151

152

153

154

155

156

157

events; however, due to the high permeability of the aquifer and the daily time step used, the assumption holds for the majority of the time.

The goal of this study was to use DFA and modeling to investigate how the proposed raises in canal stage along C111 could impact soil and bedrock water contents in low lying farmlands located between canals C-111 and C-111E. The specific objectives were to: (1) apply DFA to identify the most important factors affecting temporal variation in soil and bedrock water contents, (2) develop a simplified DFA based regression model for predicting soil and bedrock water contents as a function of canal stage, and (3) use the developed simple regression model to predict the impact of proposed incremental raises in canal stage on soil and bedrock water contents at various elevations and distances from the canal.

\section{Materials and methods}

\subsection{Experimental site}

The study was conducted in southern Miami-Dade County, Homestead, Florida, United States in a small agricultural area approximately $17 \mathrm{~km}^{2}$ (Fig. 1). The area is located east of ENP between SFWMD canals $\mathrm{C} 111$ and $\mathrm{C} 111 \mathrm{E}$ which are planned to experience increases in canal stage under the $\mathrm{C} 111$ spreader canal project. Canal stage upstream in the two canals is controlled by a remotely operated spillway at S177 and a culvert at S178, respectively (Fig. 1). C111 is the larger of the two canals and the two join to become a single canal at the southern end of the study area which is managed using a gated spillway at S18C. It is proposed that stage will be increased by modifying operation of S18C and thus affect canal stage in the reach of $\mathrm{C} 111$ between S177 and S18C. The hydrogeological system at the study site consists of the Biscayne aquifer which is a highly permeable shallow unconfined aquifer with hydraulic conductivities reported to exceed $10,000 \mathrm{~m} /$ day, which explains the high connectivity between the canals and the aquifer (Chin, 1991). The shallow nature of the water table implies that evaporation from the groundwater could impact soil water content. The topography at this site is essentially flat with elevation ranging approximately between 1.2 to $2.0 \mathrm{~m}$ above sea level NGVD 29. The climate is subtropical with 
171 dry season (November to May), which is the growing season for vegetables, and wet season (June to

172 October). Approximately two thirds of all the rain (average annual rainfall ranges between 1100 to 1524

$173 \mathrm{~mm}$ ) is received during the wet season months.

174 The soil at the study site is very shallow (10 to $20 \mathrm{~cm}$ ) with underlying limestone bedrock. According 175 to Nobel et al. (1996), the soils east of C111 vary and could be classified as either Krome and Chekika 176 very gravely loam (loamy skeletal, carbonatic, hyperthermic, Lithic Undorthents), or Biscayne Marl 177 (loamy, carbonatic, hyperthermic) based on their physical characteristics. We performed particle size 178 analysis using a standard 2-mm sieve and determined that the soils contain on average of $45 \%$ fine 179 fractions and 55\% gravel. Color analysis using the Munsell soil color charts (Munsell soil charts, 2000) 180 and the color guide in Noble et al. (1996) identified the study site soils to be broadly characterized as 181 Chekika soil series.

182 Three monitoring sites were used in this study located at 500, 1000 and $2000 \mathrm{~m}$ along a transect 183 perpendicular to canal $\mathrm{C} 111$, the three sites also had varying topographies and represented areas expected 184 to experience the greatest impact from the proposed raises in canal stage. Sites were selected to capture 185 differences in soil texture within our study area; this was done with a soil survey map and site visits. Sites 186 were also selected to ensure they were in privately owned agricultural low lying lands that were expected 187 to be impacted by the rises in water table elevation. For each site: i) GPS coordinates and elevation data 188 were collected, ii) groundwater wells were constructed and each was equipped with level loggers 189 (Levelogger, Gold Solinst Canada Ltd., 35 Todd Rd, Georgetown, Ontario, Canada) to record water table 190 elevation every 15 minutes, iii) multi-sensor capacitance probes (MSCP) (EnviroScan probes, Sentek 191 Technologies, Ltd., Stepney, Australia) were installed at each site to monitor soil and bedrock water 192 contents. Monitoring site locations are shown in Fig. 1; elevations are shown in Fig.2. Differences in the 193 length of times series at the three sites was due to differences in the dates of installation of the EnviroScan 194 probes (i.e., probes could only be installed when water was at least $50 \mathrm{~cm}$ below the ground surface) and 


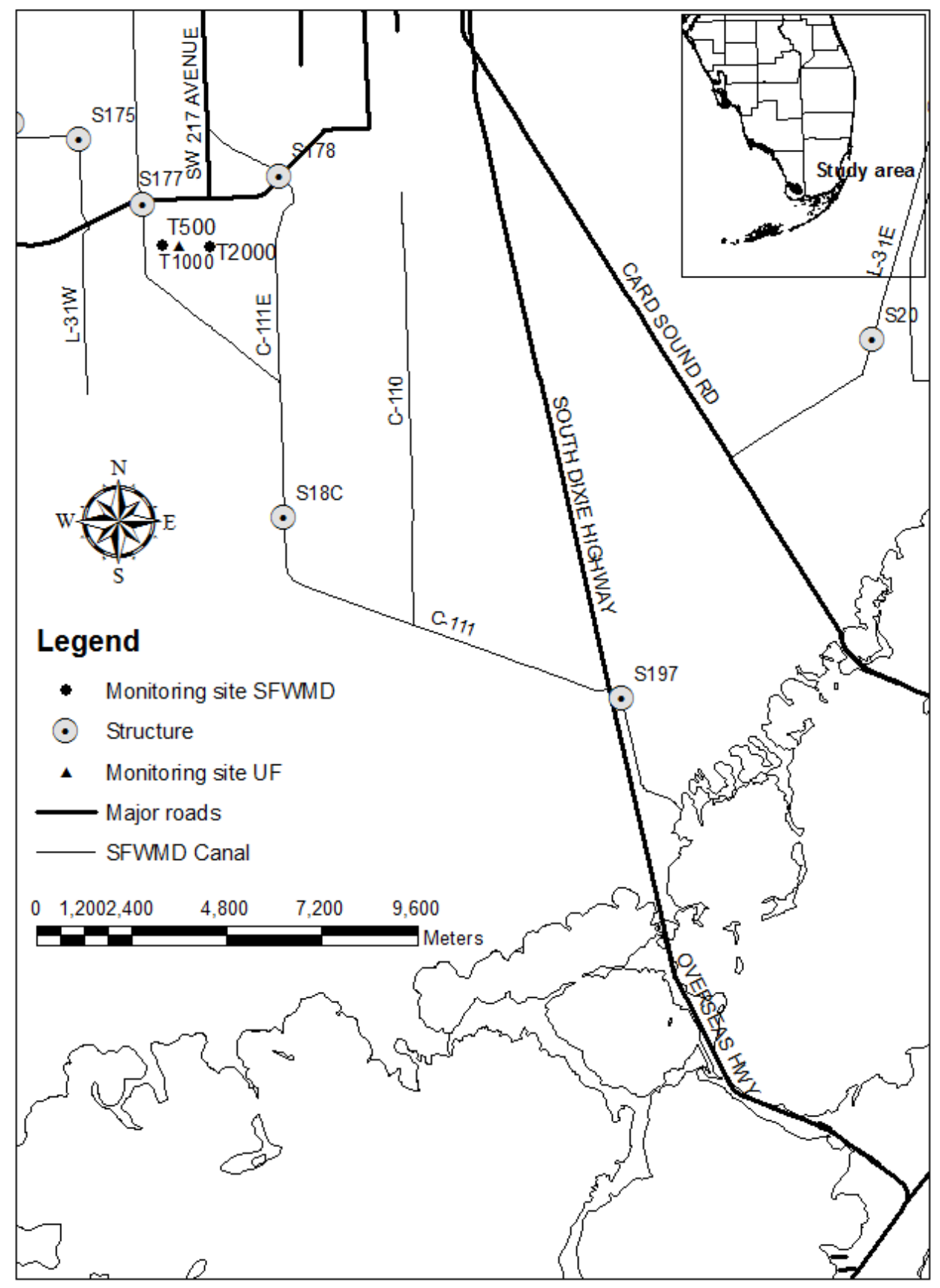

Figure 1. . Map of the study area showing Everglades National Park, Taylor Slough, Florida Bay, SFWMD canal network and low lying agricultural areas east of canal C111 in south Florida 


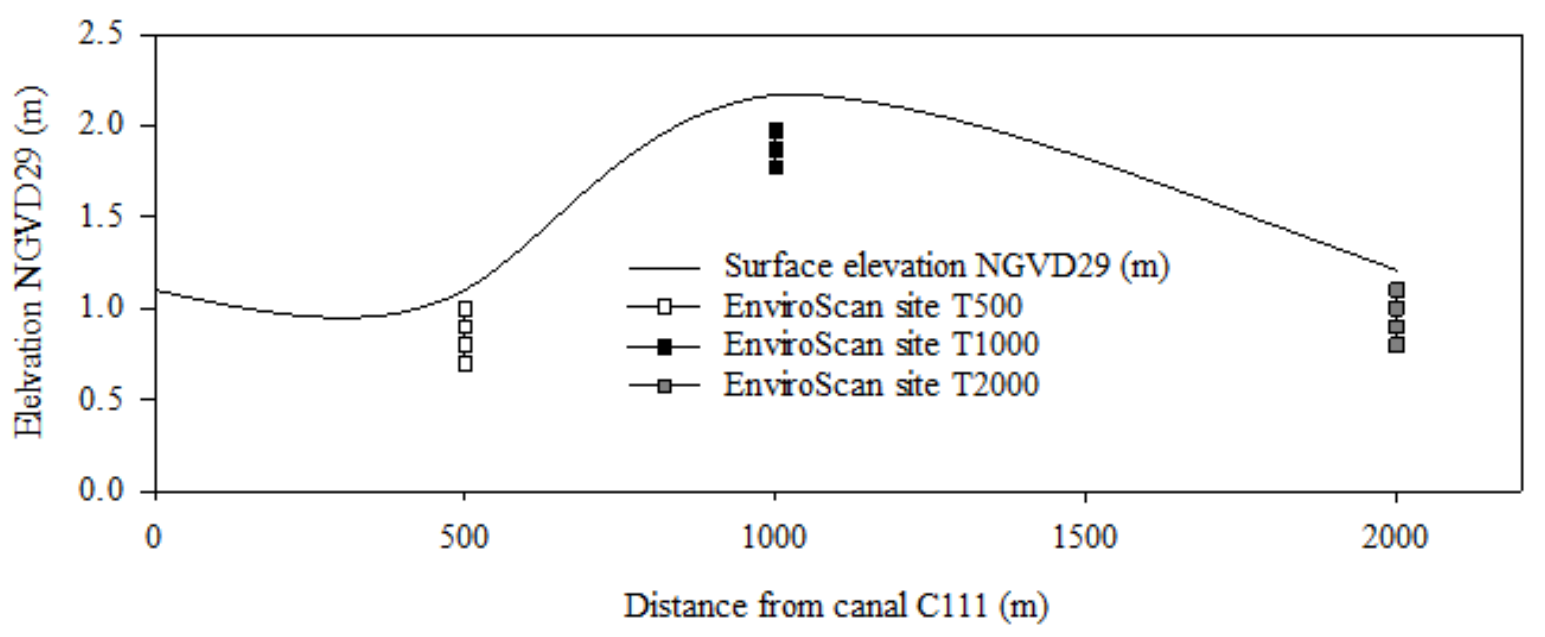

201

Figure 2. Showing a topographic changes along transect $\mathrm{T}$ and the elevation of the EnviroScan sensors at the three sites.

\subsection{Soil and bedrock water contents monitoring}

Two EnviroScan probes were installed at each site for a total of six. Each access tube with a diameter of $50.5 \mathrm{~mm}$ housed four sensors positioned at various elevations as shown in Fig. 2. The elevations correspond to 10, 20, 30 and $40 \mathrm{~cm}$ from the ground surface at each site. The top $20 \mathrm{~cm}$ typically represent the scarified soil layer which is used for crop production and the lower $20 \mathrm{~cm}$ represent the underlying limestone bedrock in which plant roots cannot penetrate. To minimize the problem of air pockets, we used fast setting cement slurry between the access tube and the soil. The purpose of installing two EnviroScan probes at the same location was to ensure that at least one probe was functioning at any given time. Due to the shallowness of the limestone bedrock at all the study sites, a motorized drill was required to bore a hole that held the access tube in a vertical position. Water content data were logged every 15 minutes and were downloaded weekly and averaged daily.

EnviroScans are an example of capacitance based sensors which measure frequency of an oscillating electrical circuit. The oscillator is coupled electrically to capacitive elements that are made of two metal cylindrical electrodes. The electrode system is arranged so the soil becomes part of the dielectric medium affected by the fringing electromagnetic field. Volumetric soil water content affects the electrical 
218

219

220

221

222

223

224

225

226

227

228

229

230

231

232

233

$234 \quad S F=F-F_{a} / F_{w}-F_{a}$

235 could be expressed eq. (1):

$C=g \varepsilon$

permittivity of the soil which in turn affects the capacitance causing the oscillation frequency to shift (IAIA, 2008) since the soil dielectric constant is a combination of mineral particles (2-4), water (80), and air (1). According to Dean et al. (1987) the oscillatory frequency from the capacitance soil water sensor

$F=\frac{1}{2 \pi \sqrt{L}}\left(\frac{1}{C}+\frac{1}{C_{b}}+\frac{1}{C_{c}}\right)^{1 / 2}$

Where $C_{b}$ is the total base capacitance and $C_{c}$ is the total collector capacitance and these represent capacitances of internal circuit elements to which the electrodes are connected, $L$ is the inductance of the coil in the circuit, and $C$ is the capacitance of the soil access tube system. Therefore capacitance of the soil access tube system, $C$, can be expressed as a function of the soil dielectric constant $(\varepsilon)$ and a value $g$ representing the geometry of the sensor as shown in eq.(2).

Differences in oscillatory frequency among sensors at the same soil and bedrock water contents were eliminated by normalizing the oscillatory frequency values using values of frequency when the sensor was surrounded by water and air. The normalized oscillatory frequency is known as the scaled frequency $(S F)$ and is estimated as in eq. 3. The manufacture default calibration equation (eq. 4) can be used to convert scaled frequency to volumetric soil water content $(\theta)$

$$
\theta=(0.792 * S F-0.0226)^{2.475}
$$

where $F$ is the oscillatory frequency value measured by the EnviroScan sensor, $F_{a}$ is frequency value when the EnviroScan probe is surrounded by air, and $F_{w}$ is the frequency value when the EnviroScan probe is surrounded by water. To avoid location specific calibration for each sensor, we use $S F$ as 
surrogate for $\theta$ for investigating the effect of various factors on soil and bedrock water contents and thus did not use eq. (4). This approach was successfully applied by Ritter et al. (2009) when studying the

241 effect of various factors on hydrologic fluxes in a forest top soil using refractive index from time-domain

242 reflectometry (TDR) as a surrogate for volumetric soil water content. Gabriel et al. (2010) observed that

243 the manufacturer's calibration equation overestimated volumetric soil water compared to the locally

244 developed calibration equation. However, they noted that despite the overestimation of volumetric soil

245 water content, the manufacturer's equation was able to reproduce temporal soil water dynamics.

246 Therefore, if the goal is to measure relative changes in water content the manufacturer's default

247 calibration equation is sufficient.

\subsection{Measurement and estimation of hydrologic variables}

Hydrologic variables including canal stage, water table elevation NGVD29 m, rainfall $(P)$, potential evapotranspiration $\left(E T_{o}\right)$ and groundwater evaporation $(E)$ were measured or estimated to assess their

251 influence on soil and bedrock water content time series.

\section{$252 \quad$ 2.3.1 Canal stage}

Canal stage data were measured at the S177 spillway for headwater (S177H) and tail water (S177T)

254 every 15 minutes but daily averages were used. Canal stage data were measured by the SFWMD and are

255 publically available from the online environmental database (DBhydro;

256 http://www.sfwmd.gov/dbhydroplsql/show_dbkey_info.main_menu). During the first phase of the C111

257 spreader canal project, the main operational adjustments will involve incrementally raising canal stage at 258 S18C (Fig. 1) which will result in increased stage in the reach of C111 between the spillways at S177 and 259 S18C.

\subsubsection{Water table elevation}


Submitted to journal of Hydrology

261

262

263

264

265

266

267

268

269

270

271

272

273

274

275

276

277

278

279

280

281

Water table elevation data were collected from three observation wells constructed at the three monitoring sites. Water table elevation was measured by the University of Florida (UF) every 15 minutes and averaged daily using a multi parameter pressure transducer at T1000 (Levelogger, Gold Solinst Canada Ltd., 35 Todd Rd, Georgetown, Ontario, Canada). Atmospheric corrections were included using a STS Barologger (Solinst Canada Ltd) in the well at T1000 (Fig. 1). Data were downloaded from the well weekly and as a quality control procedure, water table elevations were also measured manually with a Model 102 Laser water level well meter (Solinst, Canada Ltd). Wells T2000 (C111 AE) and T500 (C111AW) were installed and operated by the SFWMD and published on DBHydro.

\subsubsection{Rainfall}

Gauge adjusted Next Generation Radar (NEXRAD) rainfall data used in this study were obtained from the SFWMD. The United States National Weather Service operates two NEXRAD sites close to the study site (i.e., KBYX in Key West, FL and KAMX in Miami, FL) that provide $2 \mathrm{~km} \times 2 \mathrm{~km}$ NEXRAD rainfall data. There are tradeoffs between rainfall estimated by rain gauges and NEXRAD. Rain gauges

(e.g., tipping buckets) provide accurate point estimates of rainfall which are acceptable for frontal related rainfall events. However, in South Florida where most of the rainfall is received in summer and summer rainfall is dominated by conventional or tropical rainfall forming processes, rain gauges may fail to accurately represent the orientation of the rainfall front or fail to capture the entire rainfall event (Pathak, 2008). On the other hand, measurement of rainfall by NEXRAD relies on the raindrop reflectivity which could be affected by factors such as raindrop size and microwave signal reflection by other particles in the atmosphere. Skinner et al. (2008) showed that the best of the two measurement methods is realized by using rain gauge or tipping bucket data to adjust NEXRAD values.

\subsubsection{Ground surface potential evapotranspiration}

Ground surface reference evapotranspiration $\left(\mathrm{ET}_{\mathrm{o}}\right)$ was computed from micrometeorological data (i.e., solar radiation, temperature, relative humidity and wind speed) obtained from a Florida Automated 
285 Weather Network (FAWN; http://fawn.ifas.ufl.edu/) station located approximately $10 \mathrm{~km}$ northeast of the 286 study site at the Tropical Research and Education Center, Homestead, FL. The American Society of Civil

287 Engineers (ASCE) standardized Penman-Monteith equation was used to estimate ET $_{0}$ values (ASCE, 288 2005). We assumed a crop with the following characteristics transpiring at a potential rate: crop height 289 (0.12 m), albedo (0.23), active leaf area index (1.44), and well illuminated leaf stomatal resistance (100.8

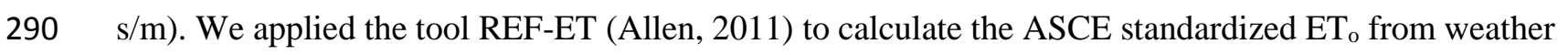
291 data.

\subsubsection{Evaporation from the water table}

Flux due to water table evaporation may influence soil and bedrock water contents. Previous studies

294 have shown that when canal influences are negligible, direct evaporation from the water table

295 significantly contributes to water table declines in the Biscayne aquifer (Merrit, 1996; Chin, 2008). Two

296 types of models are available to estimate evaporation from a water table: physically based models and

297 empirically based models. In this study, the latter was used because the former requires detailed data such 298 as coefficient of diffusion of water vapor through the soil and vapor pressure above the soil surface which 299 were not collected. Empirical models simply relate water table evaporation rate to the depth of the water 300 table below the ground surface and are used in groundwater studies (e.g., MODFLOW uses this approach; 301 Chin, 2008). We used a model similar to that proposed by McDonald and Harbaugh (1988) (eq. (5)). Chin 302 (2008) modified eq. (5) and obtained eq. (6) for south Florida conditions.

$303 \frac{E}{E_{0}}=\left(1-\frac{d}{d_{c r}}\right), \quad d_{c r}=100 *(170+8 T), \quad d<d_{c r}$

$304 \frac{E}{E_{0}}= \begin{cases}1 & d \leq d_{0} \\ 1-\frac{d-d_{0}}{d_{c r}} & d_{0}<d<d_{c r} \\ 0 & d \geq d_{c r}\end{cases}$ 
where $E$ is water table evaporation [mm/day], $E_{0}$ (same as $\mathrm{ET}_{\mathrm{o}}$ ) is the potential evaporation rate at the ground surface [mm/day], $d$ is the depth of the water table below the ground surface $[\mathrm{m}], d_{c r}$ is the critical

307 depth below which evaporation ceases $[\mathrm{m}], T$ is annual average air temperature $\left[{ }^{\circ} \mathrm{C}\right]$ which is

308 approximately $25^{\circ} \mathrm{C}$ in south Florida, $d_{0}$ is water table depth above which water table evaporation

309 proceeds at potential rate i.e., at the rate similar to the ground surface evapotranspiration [m]. Chin (2008)

310 proposed parameters $d_{0}$ and $d_{c r}$ in eq. (6) at each observation well can be estimated from the least squares

311 best fit of eq. (7) and the parameters described as eq. (8) and (9).

$312 \frac{E}{E_{0}}=\alpha-\beta d$

$313 d_{0}=\frac{\alpha-1}{\beta}$

$314 \quad d_{c r}=\frac{\alpha}{\beta}$

\subsection{Dynamic factor analysis}

316 DFA uses eq. (10) to describes a set of $N$ observed time series (Lütkepohl, 1991; Zuur et al., 2003;

317 Ritter and Muñoz-Carpena, 2006). The goal in DFA is to keep $M$ as small as possible while still obtaining 318 a good model fit. Including relevant explanatory variables helps to reduce some of the unexplained 319 variability in the observed time series.

320

$s_{n}(t)=\sum_{m=1}^{M} \gamma_{m, n} \alpha_{m}(t)+\mu_{n}+\sum_{k=1}^{K} \beta_{k, n} v_{k}(t)+\varepsilon_{n}(t)$

$321 \quad \alpha_{m}=\alpha_{m}(t-1)+\eta_{m}(t)$ 
where $s_{n}(t)$ is a vector containing the set of $N$ time series being modeled (response variables), $\alpha_{m}(\mathrm{t})$ is a (1982). The common trends in eq. (11) were modeled as a random walk (Harvey, 1989) and were predicted using the Kalman filter and EM algorithms. The regression parameters in eq. (10) are estimated using the same procedure as used in linear regression (Zuur et al., 2003). DFA was implemented using a statistical package called Brodgar Version 2.5.6 (Highland Statistics Ltd., Newburgh, UK). bedrock water contents (i.e., expressed as scaled frequency). The goodness-of-fit between modeled and observed soil and bedrock water contents were quantified using the Nash-Sutcliffe coefficient of efficiency ( $C_{\text {eff; }}$ Nash and Sutcliffe, 1970), the Akaike's Information Criteria (AIC; Akaike, 1974) and the

342 Bayesian information criterion $(B I C)$. $C_{\text {eff }}$ provides an estimate of how well a model predicts an observed 343 data set, while $A I C$ and $B I C$ are relative measures of the goodness-of-fit of a statistical model. A model 344 with the $C_{\text {eff }}$ closest to 1 and lowest $A I C$ and BIC is the preferred DFA model. Cross correlations between 
the soil and bedrock water content time series and common trends were measured using $\rho_{m, n}$. In our study $\rho_{m, n}$ close to unity implied that the common trend was highly associated with water content time series.

347 Typically canonical correlations are classified as follows: $\left|\rho_{m, n}\right|>0.75,0.5-0.75$, and $0.3-0.5$ as high, 348 moderate, and weak correlations, respectively. The influence of the explanatory variables on water 349 content time series were quantified using the magnitude of the $\beta_{k, n}$ coefficients and their associated 350 standard errors which were used with a t-test to assess whether the response variable and explanatory 351 variables were significantly related.

DFA was implemented sequentially by varying the number of common trends $M$ until a minimum $A I C$ and $B I C$ and $C_{\text {eff }}$ closest to one were achieved (Zuur et al., 2003). After identifying the minimum $M$,

354 different combinations of explanatory variables were introduced into the analysis until a combination of 355 common trends and explanatory variables that resulted in the most parsimonious model with best good356 of-fit indicators was achieved. The procedure followed here is similar to that described by Ritter et al. 357 (2009).

\subsubsection{Explanatory variables}

$365 \quad R_{n e t}=\sum_{t=1}^{t} P_{t}-\sum_{t=1}^{t} E_{o t}$ 
Submitted to journal of Hydrology

where $P_{t}$ is the total rainfall for day $t(\mathrm{~mm})$ and $E_{o t}$ is the potential evapotranspiration on day $t(\mathrm{~mm} /$ day). Cumulative water table evaporation was also used instead of daily values. To minimize multi-colinearity of explanatory variables, we used mean water table elevation instead of water table elevation at each well. Before proceeding with the DFA, multi-colinearity of explanatory variables was quantified by computing variance inflation factors (VIFs) for each explanatory variable (Zuur et al., 2007).

\subsection{Simple predictive regression model for soil water content}

The simple regression model was developed from a DFA model having the minimum number of common trends required to explain underlying common patterns in the eleven time series and explanatory variables with significant influence on modeled soil water and bedrock water content time series. To enable practical use of the simple model, DFA was performed again for the identified model using nonnormalized/non-standardized time series. After estimating the parameters through DFA the common trends were ignored in the model to derive a simple expression relating identified significant explanatory variables and soil and bedrock water contents. The period from August 25, 2010 to December 2011 was used to develop the regression model while the data from December 01, 2011 to June 30, 2012 was used to validate the new simple model. The developed simple model was then applied to predict the impact of a 6,9 and $12 \mathrm{~cm}$ increase in canal stage on soil and bedrock water contents at the study sites.

\section{Results and discussion}

\subsection{Visual exploratory analysis of experimental time series}

Visual inspection of soil and bedrock water content time series expressed as SF indicates that there were some common patterns in the temporal variation of soil and bedrock water contents at the three sites (T500, T1000 and T2000) along the transect perpendicular and east of canal C111. From February 2011 to July 2011, soil and bedrock water contents gradually decreased at all monitoring elevations and all sites (Fig. 3). The gradual decrease in soil and bedrock water contents corresponded to the decline in canal stage and water table elevation (Fig. 4). The period from April to August was characterized by 
390

pronounced drying and wetting cycles at all sites. The wetting or spikes in soil and bedrock water contents in this period correspond to the start of the rains while the drying cycles correspond to the increasing potential evapotranspiration during the same period (Fig. 4). The period from late March to July corresponds to the end of the growing season and beginning of the wet season. From August 2011 to February 2012, soil and bedrock water increased corresponding to stage operation criteria within the canal network that enhances water storage in the system.

However, there were observed differences in temporal soil and bedrock water variability at the three monitoring sites along the transect. Site T500 which is the shallowest and closest to the canal exhibited lack of temporal variation in bedrock water content at elevations less than 0.9 m NGVD29 while soil water content at $1.0 \mathrm{~m}$ NGVD29 exhibited temporal variation in the same period probably due to irrigation during the growing season. Site T1000 (i.e., approximately $1000 \mathrm{~m}$ from canal C111) exhibited the least increase in water content between March 2011 and June 2012. Unlike sites T500 and T2000, the trends in soil and bedrock water contents at T1000 were not identical to the temporal variation in canal stage or water table elevation suggesting micro-topography within the field might be affecting soil and bedrock water contents since this site had the highest elevation along the transect (Fig. 2). At site T2000 (i.e., approximately $2000 \mathrm{~m}$ from canal C111), soil and bedrock water contents for the periods between August 2010 to March 2011 and August 2011 to February 2012 were similar characterized by small temporal variation similar to those exhibited at site T500. Sites T500 and T2000 have very similar elevation (1.1 and 1.2 m NGVD29 respectively) implying that topography or ground surface elevation might exert a stronger influence on temporal variation of soil and bedrock water contents compared to distance from the canal. Differences also existed at the different monitoring elevations with bedrock water content generally higher at the lowest elevation at each site. Other reasons for observed differences in water content at the different sites could be a combination of several factors such as differences in soil surface conditions, soil and limestone bedrock heterogeneity (specifically differences in soil water 
414 retention and unsaturated hydraulic conductivity) and differences in the environments surrounding the

415 EnviroScan access tubes.

416 All the hydrologic variables monitored (Fig. 4) exhibited seasonal variations with rainfall increasing

417 during wet season (May to October) resulting in increased water table elevation and canal stage. $\mathrm{ET}_{\mathrm{o}}$ also

418 increased during the wet season. In turn, decreased depth to water table and increased $\mathrm{ET}_{\mathrm{o}}$ resulted in

419 increased $E$ (Fig. 4).The water table evaporation parameters for eq. (6) were computed following the

420 procedure described by Chin (2009) in which steady declines in water table elevation particularly in the

421 dry season when canal stage was maintained relatively constant are assumed to be caused by water table

422 evaporation. Using data from a total of six wells (i.e., the 3 wells along transect $\mathrm{T}$ and 3 additional wells

423 approximately $1 \mathrm{~km}$ north of the transect) within the vicinity of the study area, we obtained an average

424 critical depth of $1.94 \mathrm{~m}$ which is within the range of 1.5 to 2.9 earlier reported by Chin (2009). We

425 obtained a value of $0.59 \mathrm{~m}$ for the depth above which water table evaporation proceeds at the potential

426 rate which is approximately half the average value of 1.4 reported by Chin (2009). The water table

427 elevations at the three monitoring sites were very similar and also corresponded to the temporal variations

428 in canal stage on the tail water side of the spillway at S177. 


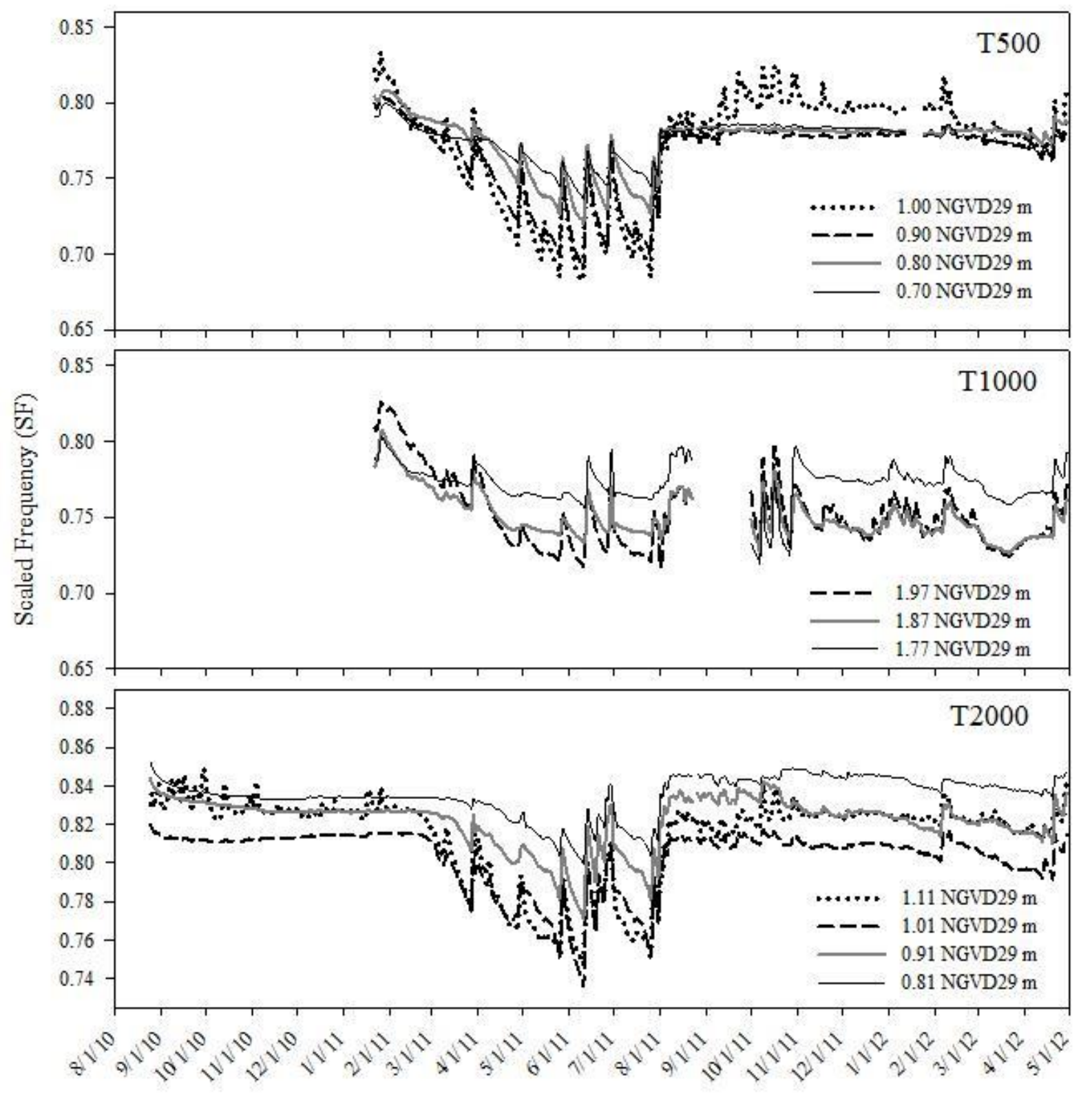

Figure 3. Temporal variation in scaled frequency (i.e., soil and bedrock water contents ) at three sites (i.e.,

431 T500, T1000 and T2000 with soil and bedrock water contents monitored at different elevations using

432 EnviroScan probes) along a transect perpendicular to $\mathrm{C} 111$ on the tail water side of the spillway at

433 structure S177 during the period August 2010 to June 2012. 


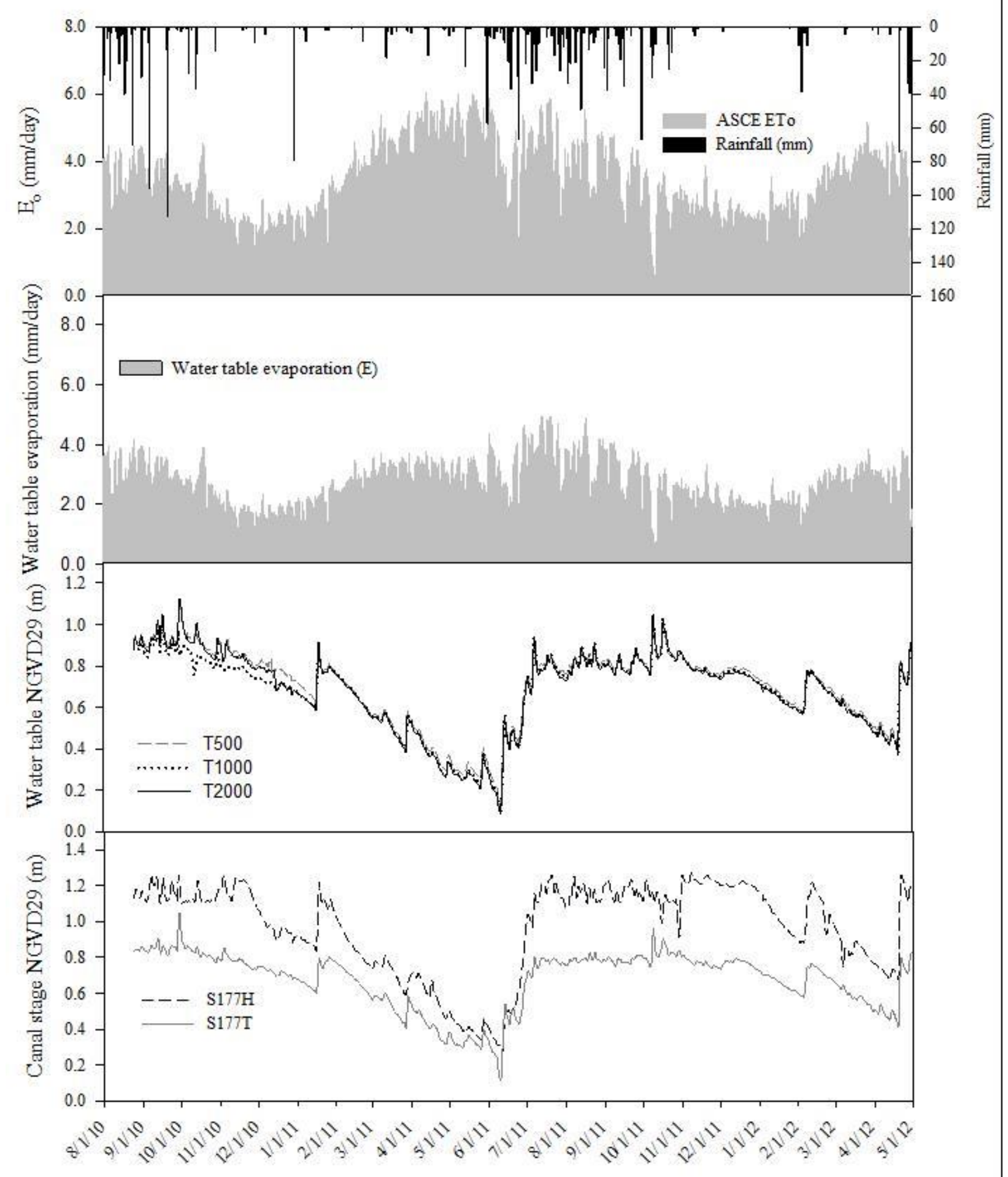

436 contents at the study site during the period August 2010 to June 2012. 


\subsection{Response and explanatory variables}

Visual inspection indicated that seasonality affects temporal variation of both response variables (i.e., soil and bedrock water contents at different elevations) and explanatory variables (i.e., $E T_{o}$, rainfall $P$, water table elevation, $E$ and canal stage). We attempted to remove seasonality effects through seasonal

441 standardization following procedures described by Salas (1993), but this approach was abandoned since it 442 resulted in poor model fit compared to the models in which seasonal effects were assumed to be masked 443 in the common trends (i.e., average $\mathrm{C}_{\text {eff }}<0.7$ and $\mathrm{C}_{\text {eff }}>0.9$, respectively). The poor model fit could be 444 attributed to loss of information resulting from seasonal standardization. Ritter et al. (2009) also reported 445 improved DFA model fit after back transforming refractive index data from a TDR as a surrogate for soil 446 water content compared to seasonally standardized refractive index.

447 To facilitate interpretation of factor loadings and comparison of regression parameters as suggested 448 by Zuur et al. (2004), all the time series were normalized. Therefore, the DFA results presented in 449 reference to objective 1 are based on normalized time series data. Prior to performing the DFA, 450 multicollinearity in explanatory variables was quantified by calculating Variance Inflation Factor (VIFs) 451 for each explanatory variable. Threshold VIF of 5 was set as the highest, high values of VIF indicate 452 multicollinearity in the explanatory variables which makes interpretation of regression results difficult 453 (Ritter et al., 2009). As expected there was high multi-colinearity between water table elevation time 454 series for different wells (VIFs > 30), but this was considerably reduced when mean water table elevation 455 at the three sites was used instead (i.e., VIFs < 2). There was also high multi-colinearity between 456 headwater and tail water canal stages at S177 (VIFs > 8) implying that these two time series could not be 457 used as explanatory variables in the same DFA model. Mean water table elevation was also correlated to 458 canal stage S177 (VIFs >10) probably due to the high hydraulic connectivity between C111 and Biscayne 459 aquifer. The correlation coefficient between canal stage and water table elevation time series was greater 460 than 0.9 . 
Submitted to journal of Hydrology

\subsection{Common trends}

We developed the DFA model by exploring common trends and explanatory variables in relation to the 11 observed water content time series. Results of the DFA model selection are summarized in Table 1. We used the $A I C$, the $B I C$ (which penalizes more strongly for over parameterization than the $A I C$ ) and the $C_{\text {eff }}$ statistic for deciding which of the DFA models with zero explanatory variables best described the response time series. Ten was the maximum number of common trends used to describe common variability in the 11 response water content time series. However, the goal of DFA is to minimize the number of common trends while maintaining a good model fit. Several models consisting of fewer numbers of common trends and noise were tested and model 4 with five common trends was determined to be the model with the minimum number of common trends required to describe the 11 response time series. Model 4 was selected since using $M>5$ resulted in negligible improvement in model goodness-offit measures while increasing the number of parameters to be interpreted. The three common trends with high $\left(\rho_{m, n} \mid>0.75\right)$ to moderate $\left(0.5<\rho_{m, n}<0.75\right)$ canonical correlations particularly at sites T500 and T2000 are shown in Fig. 5. Common trends 2 and 3 exhibited minor cross correlation with water content time series as measured by $\rho_{m, n}<0.5$ at all the sites and in the interest of brevity are not presented.

Visually, the unexplained variation in soil and bedrock water contents described by the common trends in Fig. 5 is similar to the seasonal variation of soil and bedrock water contents at sites T500, T1000 and T2000 for the period August 2010 to August 2011. There was greater uncertainty as shown by a large (95\%) confidence interval from August 25, 2010 to January 21, 2011 which is due to missing data for sites T500 and T1000 during this period. The first common trend exhibited high positive $\left(\left|\rho_{1, n}\right| \geq 0.75\right)$ correlation with soil and bedrock water content time series at sites T500 and T2000 with low surface elevation (1.1 and 1.2 m NGVD29, respectively) compared to the moderate to weak correlation at site T1000 with ground surface elevation of $2.17 \mathrm{~m} \mathrm{NGVD29.} \mathrm{Indicating} \mathrm{that} \mathrm{in} \mathrm{addition} \mathrm{to} \mathrm{other} \mathrm{factors,} \mathrm{such}$ 
484 as irrigation during the growing season, micro-topography within the field influences temporal variations

485 in soil water content as it governs the effect exerted by the water table.

486 Table 1. Dynamic Factor Analysis (DFA) models tested based on the following goodness-of-fit measures:

$487 \quad \mathrm{AIC}, \mathrm{BIC}$ and $\mathrm{C}_{\text {eff }}$

\begin{tabular}{|c|c|c|c|c|c|c|}
\hline Model & $\begin{array}{l}\text { No. of } \\
\text { common } \\
\text { trends }\end{array}$ & Explanatory variables & $\begin{array}{c}\text { No. of } \\
\text { parameters }\end{array}$ & $\mathrm{AIC}^{1}$ & $\mathrm{BIC}^{2}$ & $\mathrm{C}_{\mathrm{eff}}{ }^{3}$ \\
\hline \multicolumn{7}{|c|}{ Step I (DFA model with K=0) } \\
\hline 1 & 2 & None & 98 & -2690.50 & -2041.75 & 0.68 \\
\hline 2 & 3 & None & 107 & -4654.23 & -3945.90 & 0.84 \\
\hline 3 & 4 & None & 115 & -5830.21 & -5068.92 & 0.88 \\
\hline 4 & 5 & None & 122 & -6901.47 & -6093.84 & 0.97 \\
\hline 5 & 6 & None & 128 & -7028.76 & -6181.40 & 0.97 \\
\hline 6 & 8 & None & 137 & -7263.94 & -6357.01 & 0.97 \\
\hline \multicolumn{7}{|c|}{ Step II (DFA model with K>0) } \\
\hline 7 & 5 & $\mathrm{R}_{\text {net }}^{4}$, & 133 & -7018.644 & -6138.193 & 0.97 \\
\hline 8 & 5 & $\mathrm{R}_{\text {net }}, \mathrm{E}^{5}$ & 144 & -7797.525 & -6844.255 & 0.98 \\
\hline 9 & 5 & $\mathrm{~S} 177 \mathrm{~T}^{6}$ & 133 & -7340.981 & -6460.530 & 0.97 \\
\hline 10 & 5 & $\mathrm{~S} 177 \mathrm{~T}, \mathrm{R}_{\mathrm{net}}$ & 144 & -7542.680 & -6589.410 & 0.97 \\
\hline 11 & 5 & $\mathrm{R}_{\mathrm{net}}, \mathrm{E}, \mathrm{MWT}^{7}$ & 155 & -8052.436 & -7026.346 & 0.98 \\
\hline 12 & 5 & MWT, $\mathrm{R}_{\text {net }}$ & 144 & -7444.030 & -6490.761 & 0.97 \\
\hline 13 & 5 & $\mathbf{R}_{\text {net }}, \mathbf{E}, \mathbf{S 1 7 7 T}$ & 155 & -7922.346 & -6896.257 & 0.98 \\
\hline
\end{tabular}

$488 \quad{ }^{1}$ AIC Akaike information criterion

$489 \quad{ }^{2}$ BIC Bayesian Information Criterion

$490 \quad{ }^{3} \mathrm{C}_{\text {eff }}$ Nash-Sutcliffe coefficient calculated based all the nine observed time series

$491{ }^{4}$ Cumulative net surface recharge

$492 \quad{ }^{5} \mathrm{R}_{\mathrm{net}}$ Cumulative water at table evaporation

$493 \quad{ }^{6}$ S177T Canal stage in C111

$494 \quad{ }^{7}$ MWT Mean water table evaporation

495 

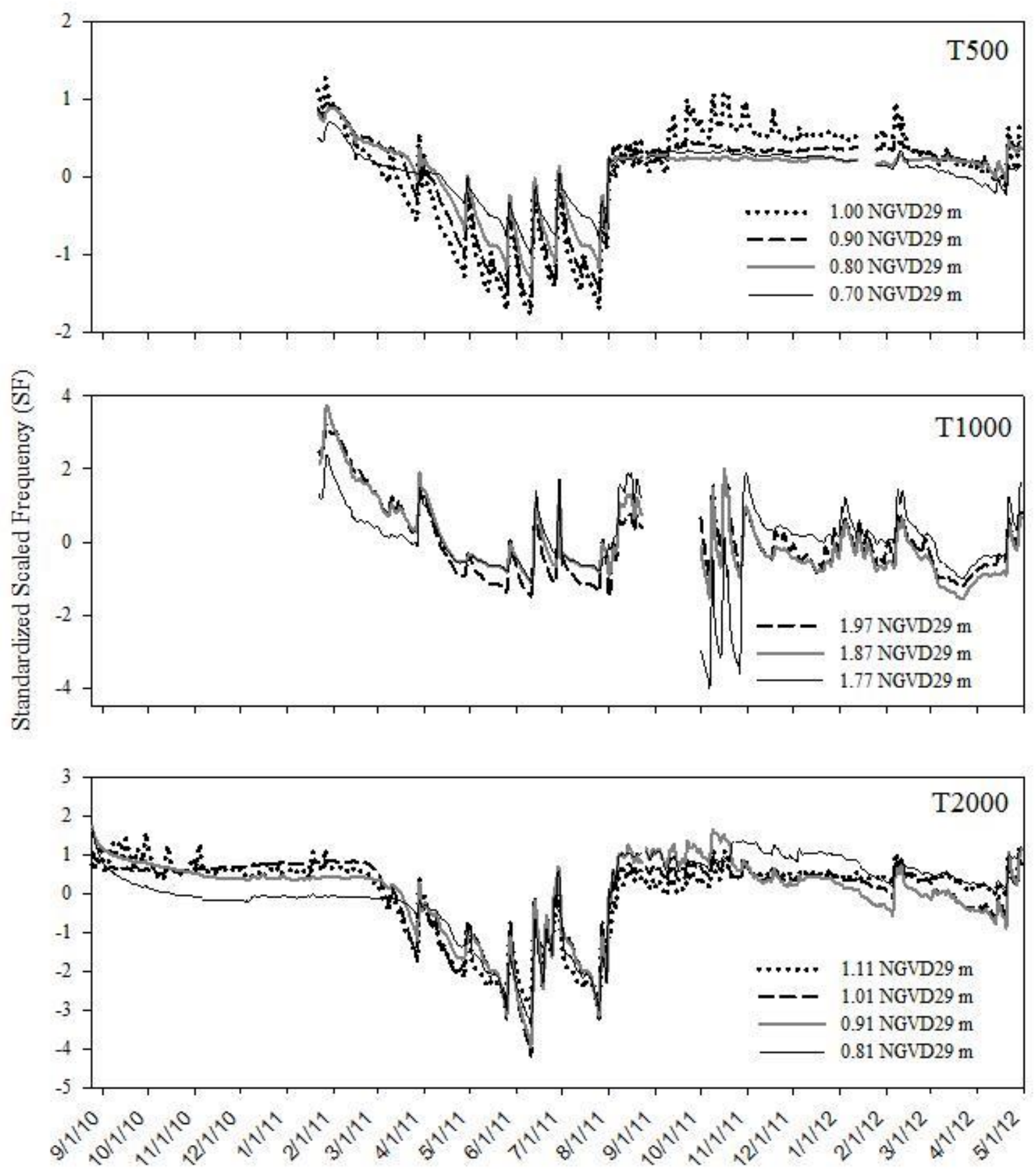

497 Figure 5. Common trends with 95\% confidence interval describing unexplained temporal variation in

498 scaled frequency as a surrogate for soil and bedrock water content and the canonical correlation for

499 quantifying the correlation between water time series and the common trends, in the nomenclature for site 
Submitted to journal of Hydrology

500

501

502

503

504

505

506

507

508

509

510

511

512

513

514

515

516

517

518

519

520

521

522

names the number represents distance from the canal in $\mathrm{m}$, and the numbers in the parenthesis represent elevation NGVD $29 \mathrm{~m}$.

\subsection{Relative contribution of explanatory variables}

Introducing net surface recharge, water table evaporation, and mean water table elevation or C111 canal stage to model 4 resulted in the best models (11 and 13). Inclusion of explanatory variables in the DFA model also produced regression parameters $\left(\beta_{k, n}\right)$ and since response and explanatory variables were normalized, the regression parameters were used to quantify the relative influence of each explanatory variable on the modeled soil and bedrock water content time series. It is worth noting that substituting mean water table elevation in model 11 with canal stage as in model 13 resulted in AIC and $B I C$ that were not substantially different and similar goodness-of-fit indicator (Table 1). Since part of the motivation for this research was to assess the effect of canal stage management on soil and bedrock water contents, further analysis was made on model 13 because canal stage data have a more consistent record compared to water table elevation data. At the study site, canal stage can be used as a good approximation to water table elevation due to the high permeability of the aquifer.

Model 13 fitted plots are shown in Figs. 6 to 8; these figures indicate that DFA modeling was successfully applied to describe temporal variations in soil and bedrock water contents at all three monitoring sites and elevations $\left(C_{\text {eff }}>0.9\right)$. Results in Table 2 indicate that net surface recharge $\left(R_{\text {net }}\right)$ had a significant influence ( $t$ value $>2)$ on the temporal variation of soil and bedrock water contents at sites T500, T1000, and T2000 but was not significant at lower elevations at sites T1000 and T2000 as shown ( $t$ value <2). The significance of $R_{\text {net }}$ could be attributed to rainfall $(P)$ patterns in the study area in which two thirds of the $P$ was received in the wet season (SFWMD, 2011) and these large amounts of net water input to the vadose zone are sufficient to maintain soil and limestone bedrock near saturation, while absence of $P$ in the dry season was responsible for the dry conditions. Lack of significance at lower 
elevations at sites T1000 and T2000 could be attributed to heterogeneity in soils and bedrock (e.g.,

524 differences in hydraulic conductivity), and differences in surface cover which influence $\mathrm{ET}_{\mathrm{o}}$.

Water table evaporation was found to not significantly influence temporal variation of soil and bedrock water contents ( $t$ value <2) at all the sites monitored. The non-significant effect of water table

527 evaporation on soil and bedrock water content could be attributed to the fact that there is sufficient water

528 for evaporation due to the shallow water table. However, the negative effect was stronger at site T1000,

529 the negative effect is due to the fact that water table evaporation is a net loss from the vadose zone 530 system. The small positive water table evaporation regression coefficient at T1000 and T2000 (Table 2)

531 could be attributed to computational numerical errors. These results are worth highlighting given the fact

532 that meteorological based methods for estimating ET $_{\mathrm{o}}$ like Penman Monteith equation are criticized for 533 ignoring evaporation from the shallow water table meaning they might under estimate total $\mathrm{ET}_{\mathrm{o}}$ losses.

534 These observations could be attributed to that fact ET ${ }_{0}$ in such cases is not limited by water availability 535 but by available energy only.

537 soil and bedrock water content temporal variations ( $t$ value $>7$ ) for most sites. This finding is significant 538 because it confirms the hypotheses that the shallow water table and canal stage are highly connected and 539 that canal stage can be used to predict soil water content at a given location. From a hydrologic

540 perspective, these results were expected because in this case canal stage is used an approximation for the 541 shallow water table which serves as the lower boundary condition for the vadose zone and therefore 542 regulates available storage during the rainy season. Based on the relative magnitudes of the regression 543 coefficients (Table 2), the overall contribution of canal stage on the respective soil and bedrock water 544 content time series is higher than that of net recharge.

545 The factor loadings $\left(\gamma_{1, n}\right)$ for the five common trends are shown in Table 2, these represent the 546 influence of each common trend on the modeled soil and bedrock water content time series at the 
547 different monitoring sites and elevations. Since the time series in the DFA were normalized, the

548 coefficients $\beta_{k, n}$ and $\gamma_{1, n}$ can be compared (Zuur and Pierce, 2004). The results indicate that trend 1 was

549 very critical for describing unexplained variation in soil water dynamics at site T2000, while common

550 trends 2 and to a lesser extent 3 were more critical for describing unexplained variation in soil water

551 content at site T1000. Site T500 was sufficiently described by the explanatory variables and constant level

552 parameters given their magnitudes were larger compared to the $\gamma_{1, n}$. Trends 4 and 5 had minor effects at

553 all the monitoring sites.

Overall at all the sites, compared to regression coefficients and the constant level parameters,

555 common trends had less influence on soil and bedrock water dynamics. However, since the values of the

556 factor loadings are not zero (i.e., they account for some unexplained variability) especially at T2000 and

557 site T1000, this implies that the information provided by the hydrologic variables used as the explanatory

558 variables in the DFA models only account for part of the unexplained variability in the temporal variation

559 of the soil and bedrock water contents. Other information such as irrigation, differences in soil surface

560 conditions, differences in the environment surrounding the EnviroScan access tube, and variation in soil

561 hydraulic properties not considered in this study might account for part of the remaining unexplained

562 variability.

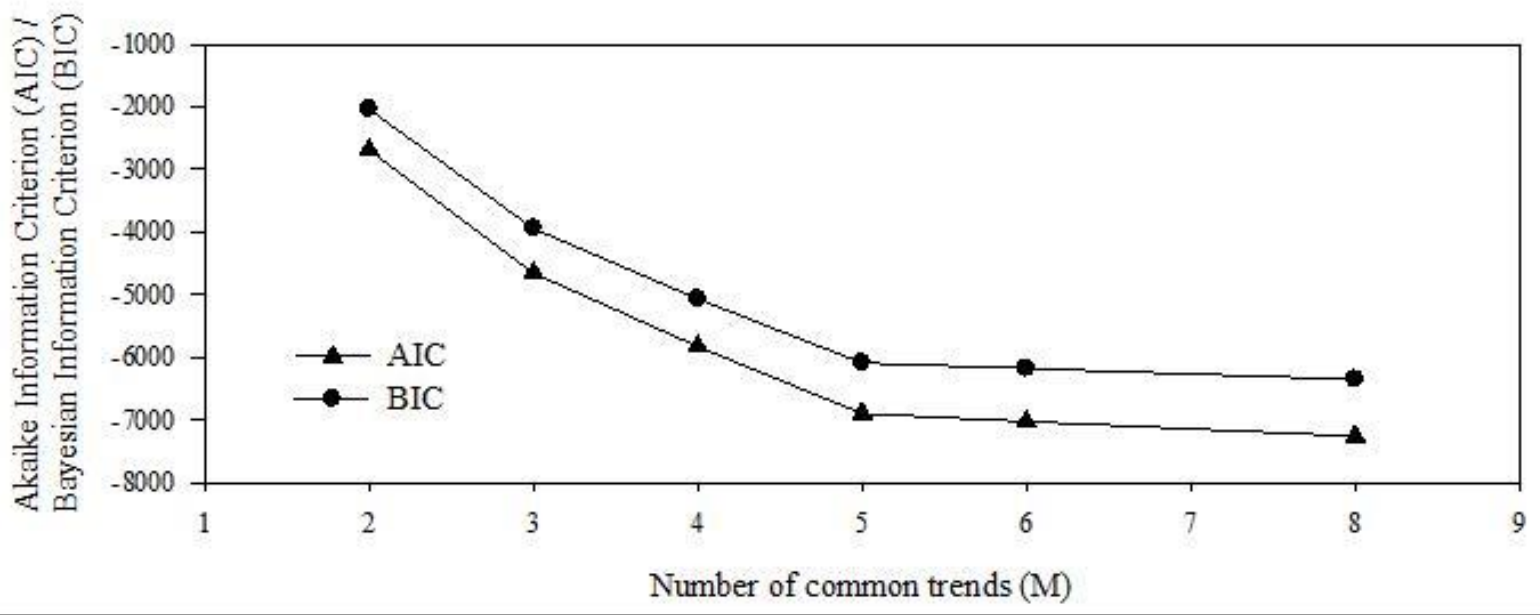


Figure 6. Fitted Dynamic Factor Model (DFM) and observed temporal variation in scaled frequency (used

565 as a surrogate for soil and rock water) in gravely loam soils and limestone bedrock at a site located $500 \mathrm{~m}$

566 along a transect from $\mathrm{C} 111$ and the numbers in the parentheses indicate elevations.
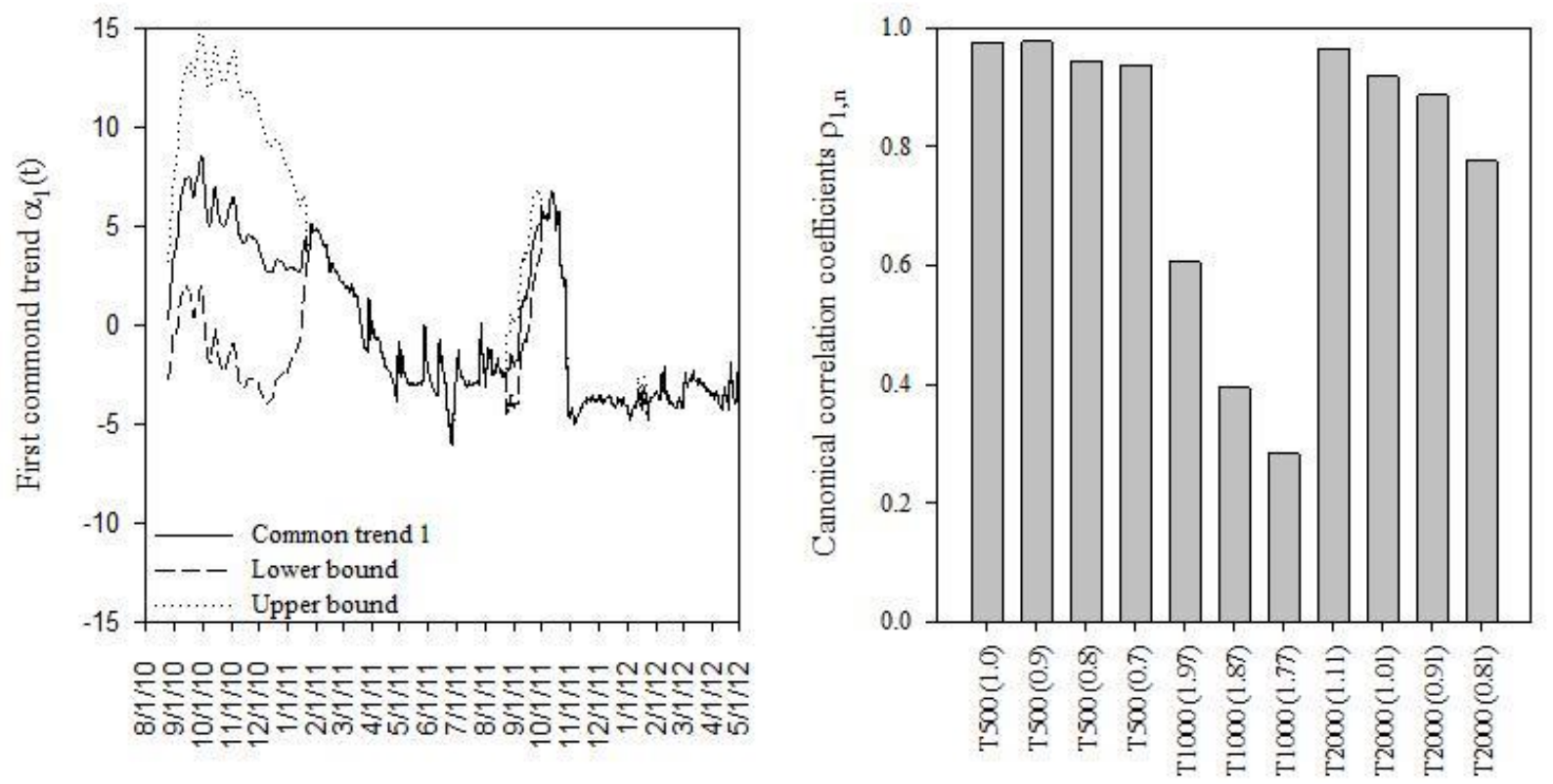

567

Figure 7. Fitted Dynamic Factor Model (DFM) and observed temporal variation in scaled frequency

569 (used as a surrogate for soil and rock water) in gravely loam soils and limestone bedrock at a site located

$5701000 \mathrm{~m}$ along a transect from $\mathrm{C} 111$ and the numbers in the parentheses indicate elevations. 

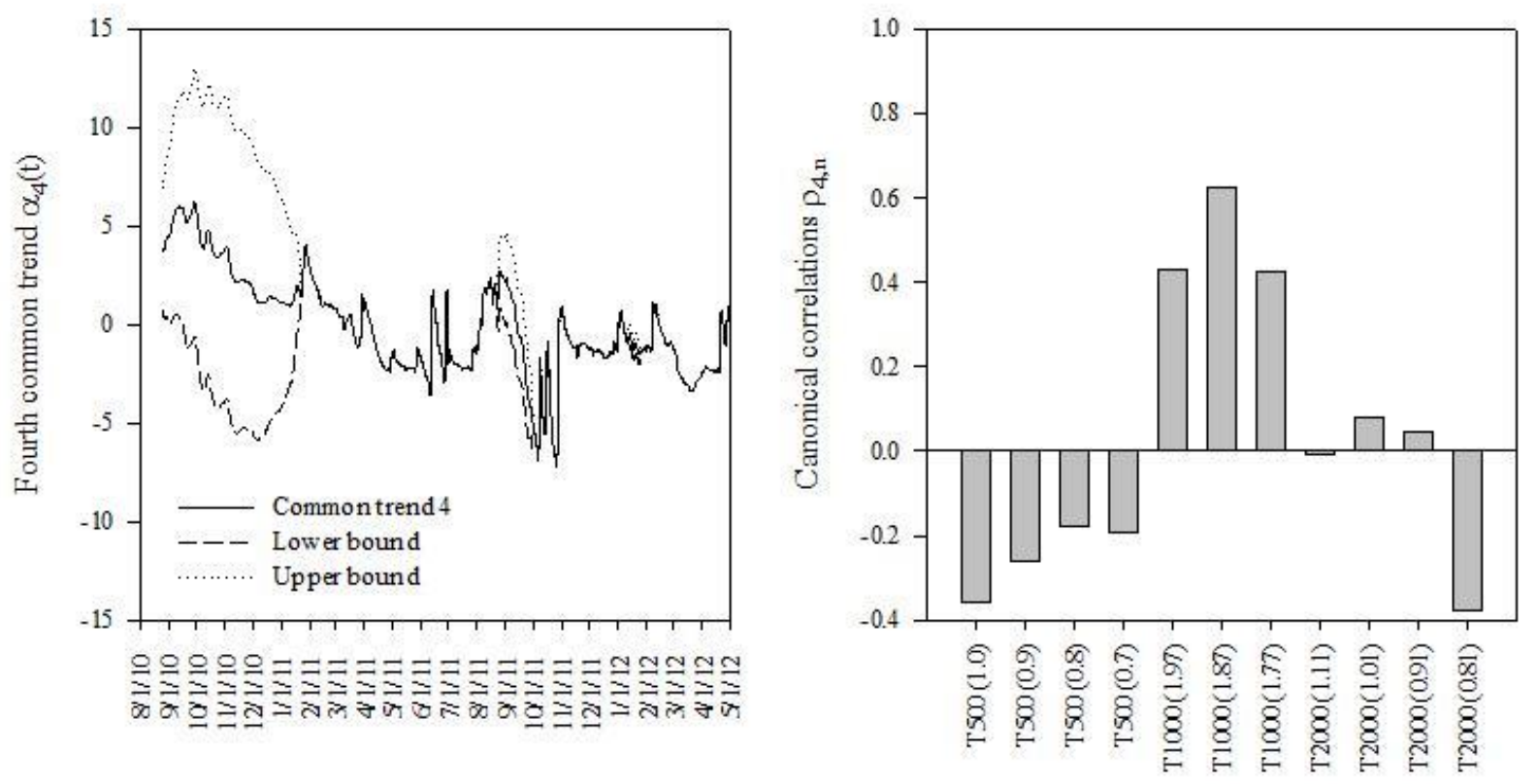

571

572 Figure 8. Fitted Dynamic Factor Model (DFM) and observed temporal variation in scaled frequency

573 (used as a surrogate for soil and rock water) in gravely loam soils and limestone bedrock at a site located

$5742000 \mathrm{~m}$ along a transect from $\mathrm{C} 111$ and the numbers in the parentheses indicate elevations.

575 Table 2. Dynamic Factor Analysis results for model 13 with 5 common trends and 3 explanatory 576 variables

\begin{tabular}{|c|c|c|c|c|c|c|c|c|c|c|}
\hline$s_{n}$ & $\gamma_{1, n}$ & $\gamma_{2, n}$ & $\gamma_{3, n}$ & $\gamma_{4, n}$ & $\gamma_{5, n}$ & $\mu_{n}$ & $\beta_{\text {Rnet }}$ & $\beta_{E}$ & $\beta_{C 11 \text { 1stage }}$ & $\mathrm{C}_{\mathrm{eff}}$ \\
\hline $\begin{array}{c}{ }^{1} \mathrm{~T} 500 \\
(1.0)\end{array}$ & 0.05 & 0.02 & 0.04 & -0.02 & -0.03 & $0.28(0.6)$ & $0.34(6.9)$ & $0.00(0.0)$ & $0.24(8.8)$ & 0.93 \\
\hline $\begin{array}{l}\text { T500 } \\
(0.9) \\
\text { T500 }\end{array}$ & 0.05 & 0.06 & 0.03 & -0.04 & -0.05 & $0.37(0.5)$ & $0.24(3.5)$ & & $0.29(8.3)$ & 0.94 \\
\hline $\begin{array}{l}(0.8) \\
\text { T500 }\end{array}$ & 0.04 & 0.06 & 0.03 & -0.03 & -0.04 & $0.34(0.6)$ & $0.20(3.2)$ & $-0.17(-0.5)$ & $0.22(7.5)$ & 0.90 \\
\hline $\begin{array}{c}(0.7) \\
\text { T1000 }\end{array}$ & 0.03 & 0.02 & 0.01 & 0.00 & -0.01 & $0.13(0.6)$ & $0.18(7.1)$ & $-0.09(-0.7)$ & $0.13(9.1)$ & 0.90 \\
\hline $\begin{array}{l}(1.97) \\
\text { T1000 }\end{array}$ & 0.04 & 0.16 & 0.13 & -0.02 & 0.00 & $0.95(0.9)$ & $0.47(3.1)$ & $-0.53(-0.7)$ & $0.62(8.7)$ & 0.85 \\
\hline $\begin{array}{l}(1.87) \\
\text { T1000 }\end{array}$ & 0.04 & 0.20 & 0.11 & 0.01 & 0.01 & & $0.38(2.1)$ & $-0.61(-0.8)$ & $0.70(8.5)$ & 0.81 \\
\hline $\begin{array}{l}(1.77) \\
\text { T2000 }\end{array}$ & 0.01 & 0.50 & 0.01 & 0.00 & 0.00 & $0.00(0.0)$ & $0.44(1.1)$ & $0.23(0.1)$ & 0.77 (4.6) & 0.67 \\
\hline (1.11) & & & & -0.01 & & & & & & 0.99 \\
\hline T2000 & 0.13 & 0.05 & 0.06 & -0.02 & 0.06 & $-0.09(-0.1)$ & $0.03(0.3)$ & $-0.03(0.0)$ & $0.68(13.2)$ & 0.90 \\
\hline
\end{tabular}


$(1.01)$

$\mathrm{T} 2000$

$\begin{array}{lllllllllll}(0.91) & 0.17 & 0.03 & 0.06 & 0.01 & -0.01 & -0.12(-0.1) & 0.05(0.4) & -0.22(-0.3) & 0.71(12.4) & 0.93\end{array}$

$\mathrm{T} 2000$

\begin{tabular}{lllllllllll}
$(0.81)$ & 0.16 & 0.04 & -0.03 & -0.02 & -0.02 & $-0.31(-0.3)$ & $0.08(0.8)$ & $0.02(0.0)$ & $0.46(8.8)$ & 0.96 \\
\hline
\end{tabular}

$\gamma$ Factor loading corresponding to common trend 1 to 5 and observation, $n=1,2,3 \ldots, 11$

$578 \mu$ Constant level parameter in dynamic factor model with associated $t$-value in parenthesis

$579 \quad \beta$ Regression parameter corresponding to the 3 explanatory variables (net recharge $\left[R_{n e t}\right]$, water table

580 evaporation [E], and canal stage in C111 [C111stage]) with associated t-value in parenthesis

$581 \quad C_{\text {eff }}$ is Nash-Sutcliffe coefficient

$582{ }^{1}$ Site name nomenclature; $\mathrm{T}$ is refers to transect name $\mathrm{T}$, number refers to distance from canal and number

583 in parentheses refers to elevation NGVD29 $\mathrm{m}$

$584 n$ number of observations

3.5 Predicting soil and bedrock water contents using a simplified dynamic factor analysis based

model

To enable practical application of the DFA model, the common trends and two of the exploratory variables included in model 13 were used in a new DFA model with non-standardized time series. This new model was referred to as model 14 . To further simplify model 14 , we ignored the common trends to derive a simple model that predicts soil and bedrock water contents as function of net recharge and canal stage expressed as eq. 13

$S F(X, Z, t)=\beta_{\text {Rnet }}(X, Z) R_{n e t}(t)+\beta_{C 111}(X, Z) S 177 T(t)+\mu(X, Z)$ are previously described and varies with elevation and distance from the canal. The coefficients for eq. 13 at all the sites and monitoring elevations are obtained from Table 3 . The $\mathrm{C}_{\text {eff }}$ in Table 3 are models that include common trends particularly for site T1000. 
602

T1000 which is affected by 4 out of the 5 common trends. Common trend number 2 appears to affect all the sites, it probably masks common variation such seasonal changes in rainfall, evapotranspiration and canal stage. Other common trends had minor effects at sites at all the other sites particularly at site T1000. The difference in response at site T1000 could be attributed to differences in elevation as shown in Fig. 2, site T1000 has a higher surface elevation and hence larger depth to water table.

The results in Table 3 also underscore the point that the effect of canal stage is stronger at low elevation sites T500 and T2000 compared to T1000. Thus, proper interpretation of modeling results in this area requires accurate quantification of micro-topography. Model performance ranged from good at sites T500 and T2000 to poor at site T1000 with root mean square error (RMSE) ranging from 0.005 to 0.01. Figs. 9 to 10 show model performance during the calibration and validation periods, after removing the common trends, it can be seen that the simple model misses the peaks but is able to generally predict the temporal variation in soil and rock water content. The simple model (eq. 13) could be improved by using location specific water table elevation since canal stage is simply a good approximation of the mean water table elevation. Another simple sigmoidal regression model to predict soil and bedrock water contents from canal stage proposed by Kaplan et al. (2010a) was tried but later abandoned due to lower $\mathrm{C}_{\text {eff }}$ (i.e., averaging 0.2). This approach is based on the physical concept of drain to equilibrium. However, for our study site this condition was hard to achieve since during the dry season irrigation was taking place and in the rainy season there was frequent rainfall hence by removing data points corresponding to rainfall or irrigation, very few data points were left to develop a useful sigmoidal model for predicting soil and bedrock water content from canal stage.

Table 3. Dynamic Factor Analysis results for model 14 with 5 common trends and 2 explanatory variables implemented with non-standardized time series

\begin{tabular}{lllllllllll}
\hline$s_{n}$ & $\gamma_{1, n}$ & $\gamma_{2, n}$ & $\gamma_{3, n}$ & $\gamma_{4, n}$ & $\gamma_{5, n}$ & $\mu_{n}$ & $\beta_{\text {Rnet }}$ & $\beta_{\text {c111stage }}$ & $C_{\text {eff }}$ & $C_{\text {eff }}$ \\
& & & & & & & & & & \\
\hline $\begin{array}{c}{ }^{1} \mathrm{~T} 500 \\
(1.0)\end{array}$ & -0.003 & 0.000 & 0.000 & 0.000 & 0.000 & 0.72 & 0.14 & 0.06 & 0.73 & 0.70 \\
$\begin{array}{c}\mathrm{T} 500 \\
(0.9)\end{array}$ & -0.001 & -0.004 & 0.000 & 0.000 & 0.000 & 0.72 & 0.11 & 0.04 & 0.61 & 0.62 \\
\hline
\end{tabular}




\begin{tabular}{ccccccccccc}
\hline T500 & & & & & & & & & & \\
$(0.8)$ & -0.001 & -0.004 & 0.000 & 0.000 & 0.000 & 0.75 & 0.09 & 0.02 & 0.51 & 0.56 \\
T500 & & & & & & & & & & \\
$(0.7)$ & -0.001 & -0.002 & 0.002 & 0.000 & 0.000 & 0.76 & 0.07 & 0.01 & 0.81 & 0.74 \\
T1000 & & & & & & & & & & \\
$(1.97)$ & 0.003 & -0.005 & -0.002 & 0.000 & 0.001 & 0.73 & 0.10 & 0.02 & 0.61 & 0.15 \\
T1000 & & & & & & & & & & \\
$(1.87)$ & 0.002 & -0.003 & -0.001 & 0.000 & 0.001 & 0.74 & 0.05 & 0.01 & 0.51 & 0.13 \\
T1000 & & & & & & & & & & \\
$(1.77)$ & 0.001 & -0.003 & 0.001 & -0.002 & 0.000 & 0.77 & 0.02 & 0.00 & 0.25 & 0.11 \\
T2000 & & & & & & & & & & \\
$(1.11)$ & 0.000 & -0.003 & -0.002 & 0.000 & 0.000 & 0.76 & 0.08 & 0.06 & 0.70 & 0.61 \\
T2000 & & & & & & & & & & \\
$(1.01)$ & 0.000 & -0.003 & 0.000 & 0.000 & 0.001 & 0.76 & 0.05 & 0.05 & 0.60 & 0.67 \\
T2000 & & & & & & & & & & \\
$(0.91)$ & 0.000 & -0.002 & 0.000 & 0.000 & 0.001 & 0.77 & 0.03 & 0.04 & 0.67 & 0.63 \\
T2000 & & & & & & & & & & \\
$(0.81)$ & -0.001 & -0.001 & 0.000 & 0.000 & 0.001 & 0.80 & 0.02 & 0.02 & 0.65 & 0.61 \\
\hline
\end{tabular}

624

625

626

627

628

629

$\gamma$ Factor loading in the dynamic factor model
$\mu$ Constant level parameter in dynamic factor model

$\beta$ Regression parameter corresponding to the 2 explanatory variables (net recharge $\left[R_{n e t}\right]$, and canal stage in C111 [C111stage])

${ }^{1}$ Nash-Sutcliffe coefficient are calculated after ignoring common trends

${ }^{2}$ Nash-Sutcliffe coefficient during validation
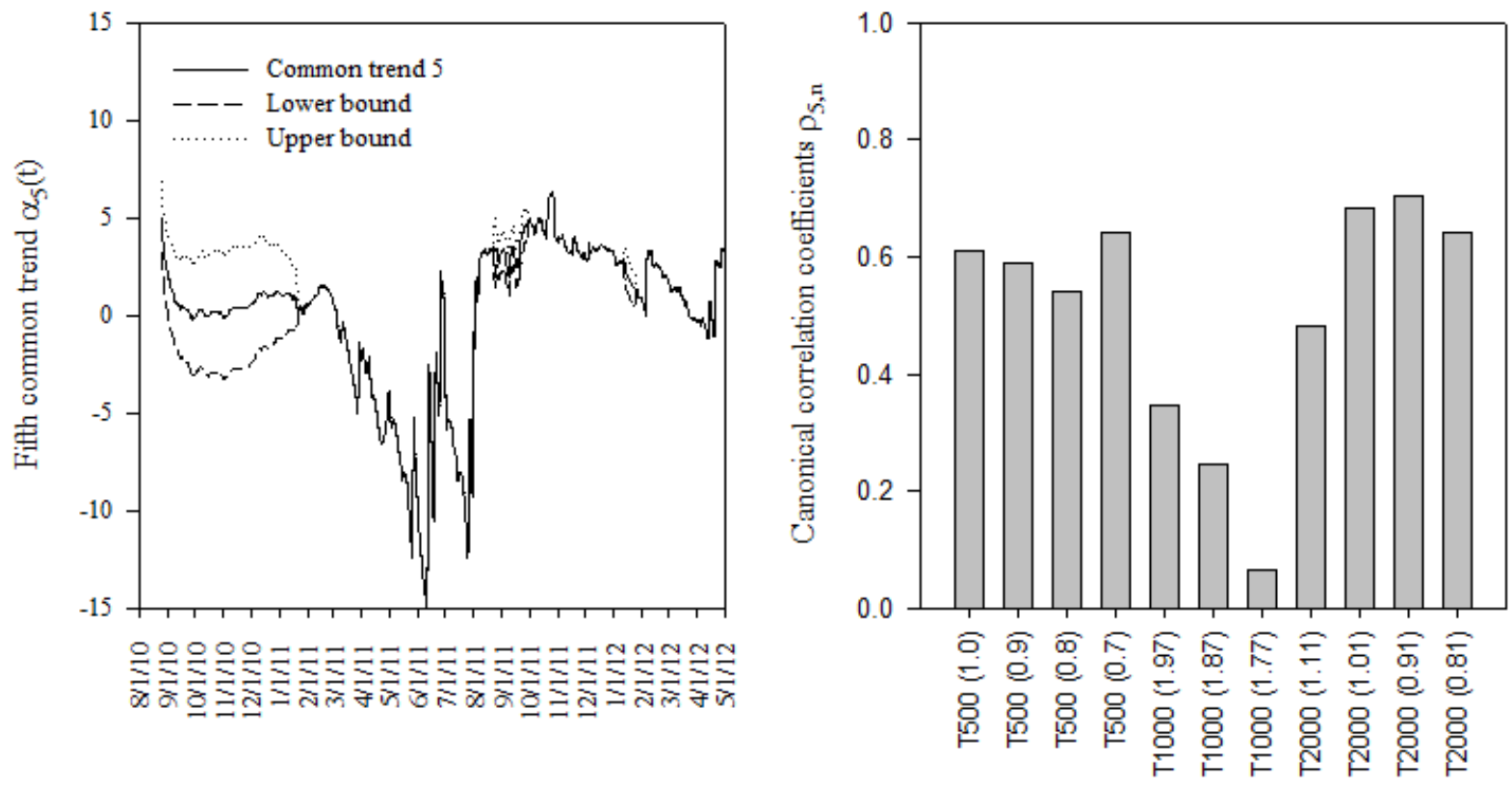

631 Figure 9. Performance of a simple model for predicting scaled frequency (used as a surrogate for soil and

632 bedrock water content) as a function of canal stage and net recharge at specific elevations in parentheses NGVD29 at a site located $500 \mathrm{~m}$ along transect T from C111. 


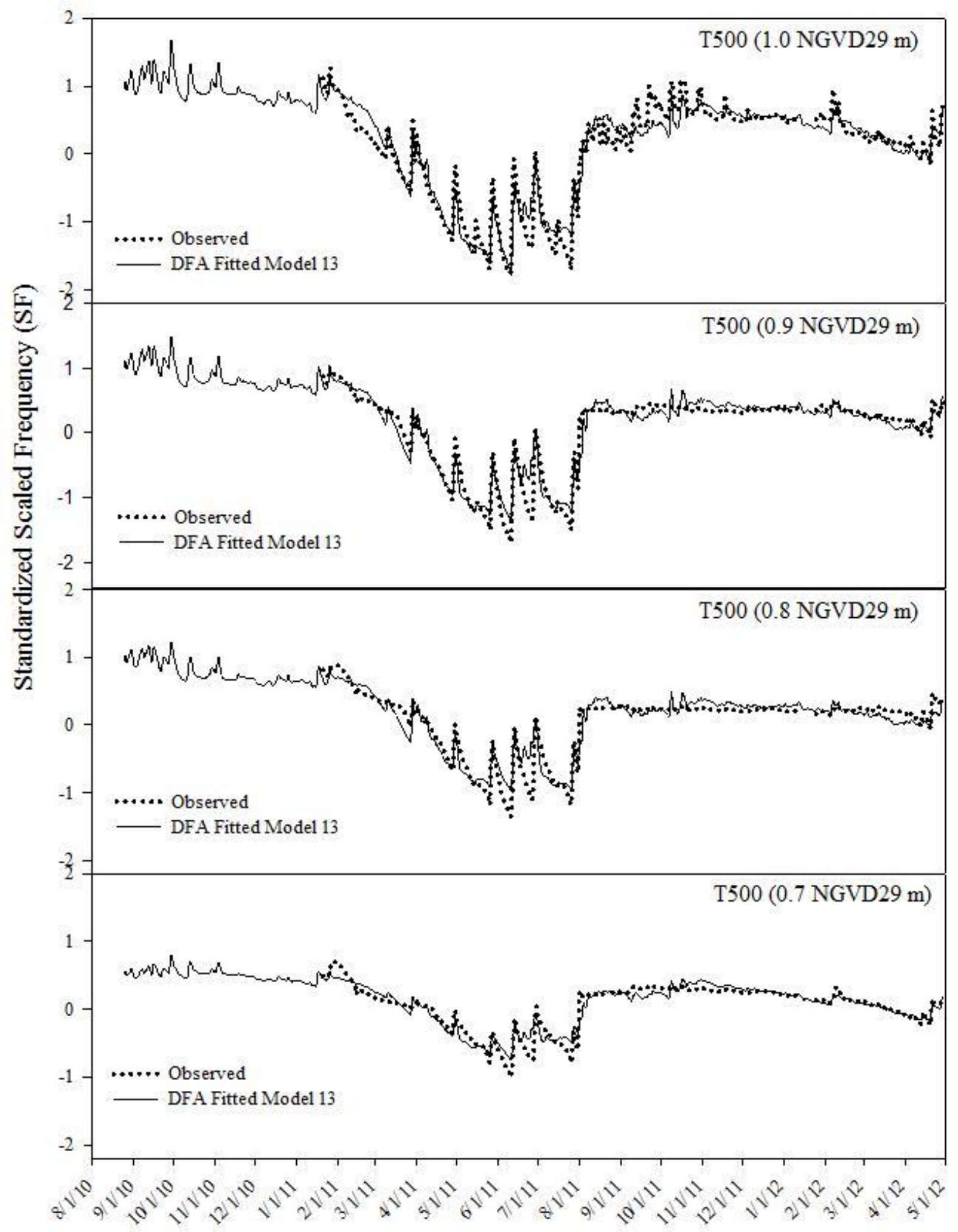


Submitted to journal of Hydrology

635

636

637

638

639

640

641

642

643

644

645

646

647

648

649

650

651

652

653

654

655

656

657

Figure 10. Performance of a simple model for predicting scaled frequency (used as a surrogate for soil and bedrock water content) as a function of canal stage and net recharge at specific elevations in parentheses NGVD29 at a site located $2000 \mathrm{~m}$ along transect $\mathrm{T}$ from C111.

\subsection{Assessing the impact of proposed operational changes in C111 canal stage management on soil} and bedrock water contents

The low lying agricultural areas east of canal C111 are anticipated to experience the greatest impact from the proposed changes in C111 stage operation (i.e., canal stage increases of 6, 9, and $12 \mathrm{~cm}$ ); a simple DFA based regression model eq. 13 was proposed to predict the soil and bedrock water contents as a function of canal stage. We considered the period from January 01 , 2012, to June 30, 2012 for the analysis. Increases in canal stage were computed by simply adding the proposed incremental rises in canal stage to the daily canal stage recorded at S177T while $P$ and $\mathrm{ET}_{\mathrm{o}}$ from the original dataset were not changed.

The results from using this simplified DFA based model (Figs. 11 and 12) indicate that the proposed increases in canal stage were predicted to have changes in daily mean SF for the study period (i.e., which is used as a surrogate for soil and bedrock water contents) of $<1 \%$ at all sites and all elevations monitored. The range in daily SF differences was 0.065 to -0.024 and 0.075 to -0.041 at sites T500 and T2000 respectively, which indicates that the simple model over predicted and under predicted SF on certain days during the study period. However, note that the daily differences in SF are not substantially large, this may be attributed to already high values of soil and bedrock water contents observed in the area. On an event basis the potential to flood or saturate the root zone would depend on the size of the storm and storm contingency planning for lowering of canal stage in anticipation of heavy storms. Since we showed using DFA that soil and bedrock water contents were significantly affected by canal stage and net recharge. 
Submitted to journal of Hydrology

The simple model used in this evaluation was more accurate at sites T500 and T2000 and therefore results at these two sites would be considered with less uncertainty. Soil and bedrock water responses to incremental raises in canal stage were not computed for site T1000 since results at this site would be considered less accurate (greater uncertainty) because model performance was very poor at this site. Figs. 11 and 12 show that changes in soil and bedrock water contents were more noticeable at the highest elevation. However, at the lowest elevations monitored the difference between mean SF before and after all increments was zero at T500. These observations could be attributed to the fact that low elevation sites are normally close to saturation. For example, at site T500 (0.7) when water elevation was above the sensor (implying saturated conditions), SF was recorded as 0.786 compared to average SF of 0.775 for the study period meaning small changes in water table may not result in substantial changes in soil water content since the pores are already near saturation.

It is worth noting that the simple model developed above should be applied with the following limitations in mind. The model does not account for water input from irrigation and therefore would under predict soil and bedrock water content during the growing season, the model also uses canal stage as an approximation for water table elevation at a specific location although the two are usually close there may be deviations especially after large rainfall events, it ignores water content drivers that were masked in the common trends, and lastly the simple model ignores the effect of $E$ which might vary based on micro-topography within the field as well as differences in land surface cover conditions. Finally, although the simplified DFA based model is empirical in nature, the results suggest it can be used as a preliminary tool to relate the potential impacts of surface water management decisions on soil and bedrock water contents in low lying farmlands adjacent to canal C111. This is because during the duration of the study, we 
681 able to capture a wide range of variation in canal stage and water table elevation e.g., on June 10,

6822011 we recorded canal stage and groundwater table elevation of $0.14 \mathrm{~m} \mathrm{NGV29}$ which is lower

683 than the optimum design stage of $0.6 \mathrm{~m}$ for the reach of $\mathrm{C} 111$ between S $18 \mathrm{C}$ and S177 under

684 current canal stage operational criteria. During the summer of 2011 (on October 09, 2011) we

685 recorded canal stage and groundwater levels as high as 0.9 and $1.02 \mathrm{~m} \mathrm{NGVD29}$ which is close

686 to the level supposed to trigger the spillway to open at S177 under current operational criteria.

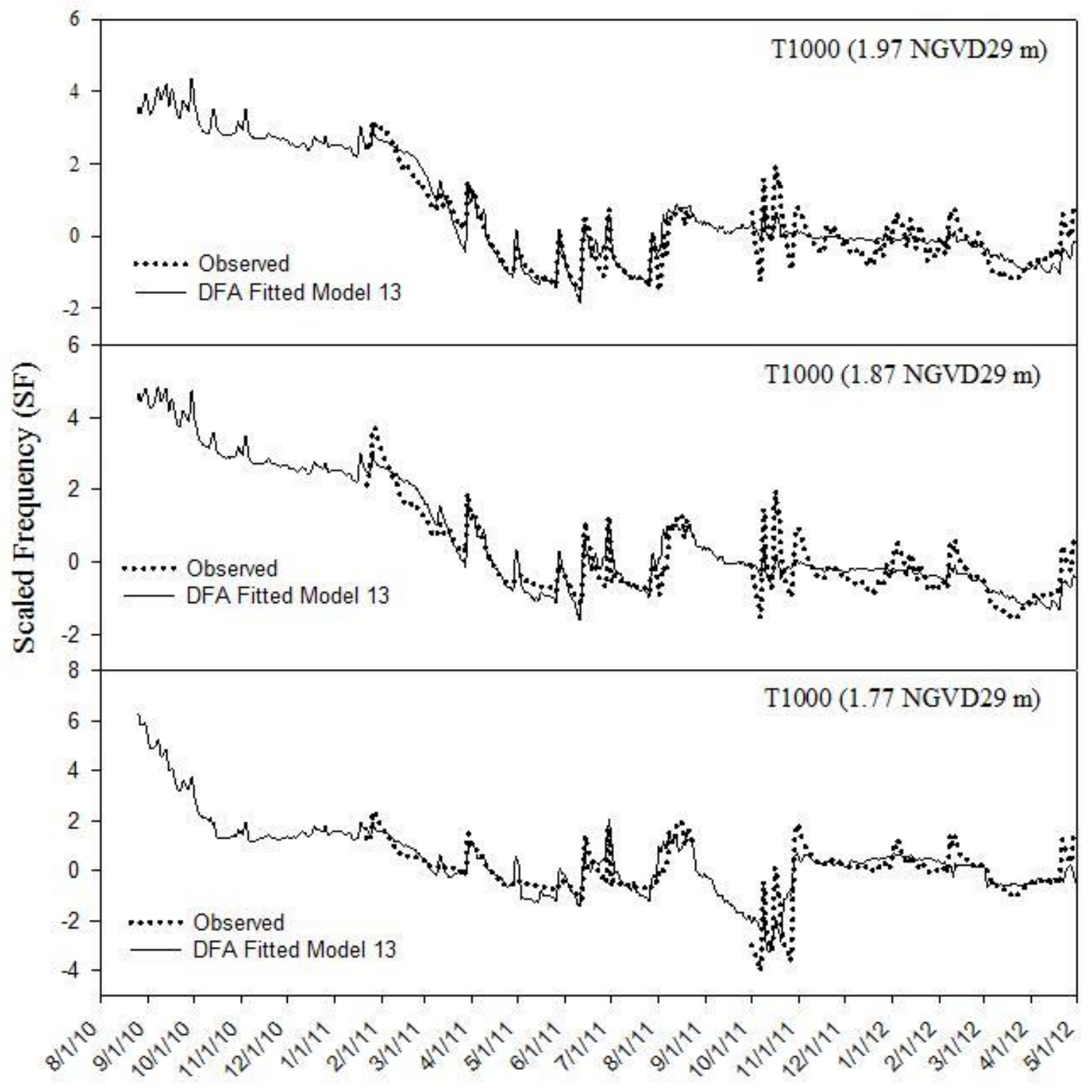


Figure 11. Boxplots showing soil and rock water content as measured using scaled frequency at site T500 before and after 6, 9 and $12 \mathrm{~cm}$ increase canal at structure $\mathrm{S} 18 \mathrm{C}$ along $\mathrm{C} 111$.

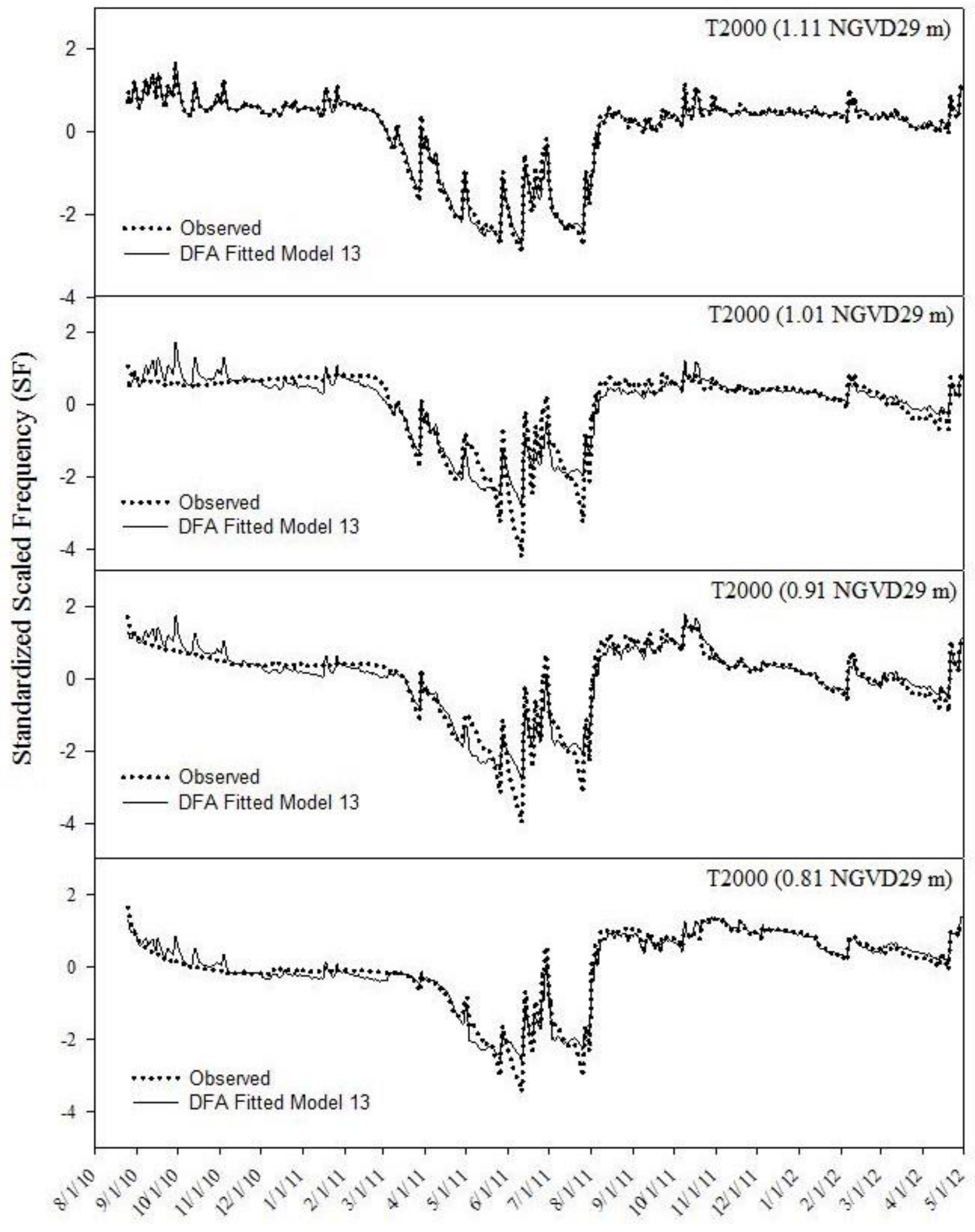


Submitted to journal of Hydrology

691 Figure 12. Boxplots showing soil and rock water content as measured using scaled frequency at site 692 T2000 before and after 6, 9 and $12 \mathrm{~cm}$ increase canal at structure S18C along C111. 
Submitted to journal of Hydrology

694

695

696

697

698

699

700

701

702

703

704

705

706

707

708

709

710

711

712

713

714

715

716

717

718

\subsection{Summary and Conclusions}

The response of soil and bedrock water contents to incremental raises in canal stage proposed under the C111 spreader canal project whose goal is to restore the hydrology of ENP while maintaining flood protection in the adjacent agricultural areas was investigated using DFA. The study objectives were to use DFA to identify the important factors driving temporal variation in soil and bedrock water content above the shallow water table at the study site, develop a simple model for predicting soil water content as a function of canal stage and assess the effect of the proposed incremental raises in canal stage on soil and bedrock water contents. Five was the minimum number of common trends required to account for the unexplained variation in the eleven observed soil and bedrock water content time series while producing an acceptable model fit. Introduction of explanatory variables i.e., net recharge, water table evaporation, and canal stage or water table elevation to the DFA model resulted in lowering AIC and BIC values while $\mathrm{C}_{\text {eff }}$ values did not substantially change. Evaluation of the regression coefficients indicated that net recharge and canal stage had significant effects on temporal variation of soil and bedrock water contents while the effect of water table evaporation was non-significant. Based on the magnitude of the regression coefficients, canal stage had the greatest influence on the temporal variation of soil and bedrock water contents at all elevations and distances from the canal at the locations monitored. The effect of canal stage and mean water table elevation in the DFA model was similar confirming the high hydraulic connectivity between the canal and Biscayne aquifer.

Based on the high connectivity between surface water in the canal and Biscayne aquifer, a simple DFA based regression model (DFA model in which the common trends were removed), was developed to predict soil and bedrock water contents as a function of canal stage and net recharge at various elevations.

The performance of the simplified regression model was described as good to acceptable at sites with low elevation (i.e., water table elevation within $1 \mathrm{~m}$ from the ground surface) and poor at the location at with water table depth greater than $1.5 \mathrm{~m}$. These findings highlight the effect of micro-topography within the field on soil water content. The study also revealed that factor loadings were not zero for all the common 
Submitted to journal of Hydrology

719

720

721

722

723

724

725

726

727

728

729

730

731

732

733

734

735

736

737

738

739

740

trends suggesting that the explanatory variables (net recharge and canal stage) used in the DFA model are not sufficient to explain all the observed variations in the soil and bedrock water content time series.

The effect of the proposed 3 incremental raises in canal stage on soil and bedrock water content was simulated using the developed simple DFA based regression model for a total of 181 days beginning January 01,2012 . The results based on the data collected indicate that the proposed raises in canal stage would result in negligible changes in average soil and bedrock water contents at low elevations monitored in this study based. Changes in soil water content near the ground surface were more noticeable. The DFA based regression model developed is limited in its prediction ability to the range of canal elevations and net recharge by which it was developed. The uncertainty in predictions could be minimized by continuously updating the regression coefficients and constant level parameters as more data on response and explanatory variables are collected. The results of the regression model could be further evaluated using physically based modeling approaches. The approach used in this study could be applied to any system in which detailed physical modeling would be limited by inadequate information on parameters or processes governing the physical system.

\section{Acknowledgements}

The authors would like to thank the South Florida Water Management District for providing the funding for this study, the University of Florida IFAS Tropical Research and Education Center, and the University of Florida Agricultural and Biological Engineering Department, Mr. Vito Strano and Mr. Sam Accursio for allowing us to use their lands and Mrs. Tina Dispenza for her contribution towards data collection and processing. We also like to thank the three anonymous reviewers whose comments and suggestions greatly improved this manuscript. 
Submitted to journal of Hydrology

741

742

743

744 745

746

747

748

749

750

751

752

753

754

755

756

757

758

759

760

761

762

763

\section{References}

Akaike, H., 1974. A new look at the statistical model identification. IEEE Trans. Automat. Control 19, $716-723$.

ASCE, 2005., The ASCE Standardized Reference evapotranspiration Equation. Task Committee on Standardization of Calculation of Reference ET. Environment and Water Resources Institute of ASCE. 200 p.

Allen, R., 2011. REF-ET: Reference Evapotranspiration Calculation Software. User Manual.

Barquin, L.P., Migliaccio, K.W., Muñoz-Carpena, R., Schaffer, B., Crane, J.H., Li, Y.C., 2011. Shallow Water Table Contribution to Soil-Water Retention in Capillary Fringe of a Very Gravelly Loam Soil of South Florida. Vadose Zone J, 10:1-8.

Chin, D., 1991. Leakage of clogged channels that partially penetrate surficial aquifers. ASCE J. Hydraulic Engineering. 117, 467-488.

Chin, D., 2008. Phenomenological models of hydrologic processes in south Florida. J. Hydrol. 349, 230243.

Dean, T.J., Bell J.P. Baty A.J.B., 1987. Soil moisture measurement by an improved capacitance technique. Part 1: sensor design and performance. Journal of Hydrology 93:67.

Dempster, A.P., Laird, N.M., Rubin, D.B., 1977. Maximum likelihood from incomplete data via the EM algorithm. J.R. Stat. Soc. Ser. B 39, 1-38.

Duwig, C., Normand, B., Vauclin, M., Vachaud, G., Green, S.R., Becquer, T., 2003. Evaluation of the WAVE model for predicting nitrate leaching for two contrasted soil and climate conditions. Vadose Zone J. 2, 76-89.

Gabriel, J. L., Lizaso J.I., Miguel, Q., 2010. Laboratory versus Field Calibration of Capacitance Probes. Soil Sci Soc Am J. 74, 593-601. 
Submitted to journal of Hydrology

764

765

766

767

768

769

770

771

772

773

774

775

776

777

778

779

780

781

782

783

784

785

786

Genereux, D., Slater, E.,1999. Water exchange between canals and surrounding aquifer and wetlands in the Southern Everglades, USA. Journal of Hydrology 219 (1999), 153-168.

Geweke, J.F., 1977. The dynamic factor analysis of economic time series models. In: Aigner, D.J., Goldberger, A.S. (Eds.), Latent Variables in Socio-economic Models. North-Holland, Amsterdam, pp. $365-382$.

Harvey, A.C., 1989. Forecasting, structural time series models and the Kalman filter. Cambridge Univ. Press, New York.

Kaplan, D., Muñoz-Carpena, R., Wan, Y., Hedgepeth, M., Zheng, F., Roberts, R., Rossmanith, R., 2010a. Linking river, floodplain, and vadose zone hydrology to improve restoration of a coastal river impacted by saltwater intrusion. J. Environ. Quality 39 (5), 1570-1584. doi:10.2134/jeq2009.0375.

Kaplan, D., Muñoz-Carpena, R., Ritter, A., 2010b. Untangling complex groundwater dynamics in the floodplain wetlands of a southeastern U.S. coastal river. Water Resour. Res. 46, W08528-10. doi:10.1029/2009WR009038.

Kaplan, D., Muñoz-Carpena R., 2011. Complementary effects of surface water and groundwater on soil moisture dynamics in a degraded coastal floodplain forest. J. of Hydrol. 398, 221-234.

Lütkepohl, H., 1991. Introduction to multiple time series analysis. Springer- Verlag, Berlin.

Márkus, L., Berke, O., Kovács, J., Urfer, W., 1999. Spatial prediction of the intensity of latent effects governing hydrogeological phenomena. Environmetrics. 10, 633-654.

McDonald, M.G., Harbaugh, A.W., 1988. A modular three-dimensional finite-difference ground-water flow model. Techniques of Water Resources Investigations of the United States Geological Survey, Book 6, Chapter A1, US Geological Survey, Reston, Virginia.

Merritt, M.L., 1996. Simulation of the water table altitude in the Biscayne aquifer, Southern Dade County, Florida, water years1945-89. Water-Supply Paper 2458, US Geological Survey. 
Submitted to journal of Hydrology

787

788

789

790

791

792

793

794

795

796

797

798

799

800

801

802

803

804

805

806

807

808

809

810

Muñoz-Carpena, R., Ritter, A., Li, Y.C., 2005. Dynamic factor analysis of groundwater quality trends in an agricultural area adjacent to Everglades National Park. J. Contam. Hydrol. 80, 49-70.

Muñoz-Carpena, R., Ritter, A., Bosch, D.D., Schaffer, B., Potter, T.L., 2008. Summer cover crop impacts on soil percolation and nitrogen leaching from a winter corn field. J. Agricultural Water Management. 95, 633-644.

Munsell Soil Color Charts., 2000. Revised Edition. Greta G. Macbeth. New Windsor, NY.

Nash, J.E., Sutcliffe, J.V., 1970. River flow forecasting through conceptual models: Part 1-A. Discussion of principles. J. Hydrol. 10, 282-290.

Nobel, C.V., Drew, R.R.W., Slabaugh, J.D., 1996. Soil survey of Dade County Area, Florida, U.S. Department of Agriculture, NRCS Report, Washington, DC.

Pathak, S. C., 2008. South Florida Water Management District. South Florida Environmental Report Volume I. Appendix 2-1. Pg. 64. 3301 Gun Club Road, West Palm Beach, FL. Available online at:http://my.sfwmd.gov/portal/page/portal/pg grp sfwmd sfer/portlet sfer/tab2236041/volume1/v ol1_table_of_contents.html.

Ritter, A., Regalado, C.M., Muñoz Carpena R., 2009. Temporal common trends of topsoil water dynamics in a humid subtropical forest watershed. Vadose Zone J, 8(2), 437-449.

Ritter A., Muñoz-Carpena, R., 2006. Dynamic factor modeling of ground and surface water levels in an agricultural area adjacent to Everglades National Park. J. Hydrol. 317, 340-354.

Salas, J.D., 1993. Analysis and modeling of hydrologic time series. p. 19.1-19.72. In D.R. Maidment (ed.) Handbook of hydrology. McGraw-Hill, New York.

Schaffer, B.,1998. Flooding Responses and Water-use Efficiency of Subtropical and Tropical Fruit Trees in an Environmentally-sensitive Wetland. Annals of Botany 81, 475-481. SFWMD, 2011. Past and Projected Trends in Climate and Sea Level for South Florida. Hydrologic and Environmental Systems Modeling. 3301 Gun Club Road West Palm Beach, Florida 
Submitted to journal of Hydrology

811 Shumway, R.H., Stoffer D.S., 1982. An approach to time series smoothing and forecasting using the EM algorithm. J. Time Ser. Anal. 3, 253-264.

813 Šimůnek, J., van Genuchten, M. Th., Šejna, M., 2008. Development and applications of the HYDRUS and STANMOD software packages, and related codes, Vadose Zone J.7 (2), 587-600.

Skinner, C., Bloetscher, F., Pathak, C.S., 2008. Comparison of NEXRAD and Rain Gauge Precipitation Measurements in South Florida. J. of Hydrologic Engineering. 14(3), 248-260.

U.S. Army Corps of Engineers, and South Florida Water Management District, 2009. Comprehensive Everglades Restoration Plan: C-111 spreader canal western project: Draft integrated project implementation report and environmental impact statement.

USDA Soil Conservation Service. U.S. Department of Agriculture Handbook 18.

USDA National Agricultural Statistics Service for Miami-Dade County, Florida 2007. Available at: http://www.agcensus.usda.gov/Publications/2007/Online_Highlights/County_Profiles/Florida/cp12

Vanclooster, M., Viaene, P., Diels, J., Christiaens, K., 1995. WAVE: A mathematical model for 825 simulating water and agrochemicals inthe soil and vadose environment. Reference and user's manual (release2.0). Institute for Land and Water Management, Katholieke UniversiteitLeuven, Leuven, Belgium.

Water Resources Development Act, 2000. PUBLIC LAW 106-541—DEC. 11, 2000. http://www.fws.gov/habitatconservation/omnibus/wrda2000.pdf Retrieved July-23-2010.

Zou, S., Yu, Y., 1999. A dynamic factor model for multivariate water quality time series with trends. J. of Hydrol 178 (1-4), 381-400.

832 Zuur, A.F., Ieno, E.N., Smith, G.M., 2007. Analysing ecological data. Springer- Verlag, Berlin.

833 Zuur, A.F., Pierce, G.J., 2004. Common trends in Northeast Atlantic squid time series. J. Sea Res. 52, 5772. 
Submitted to journal of Hydrology

835 Zuur, A.F., Fryer, R.J., Jolliffe, I.T., Dekker, R., Beukema, J.J., 2003. Estimating common trends in multivariate time series using dynamic factor analysis. Environmetrics. 14 (7), 665-685. 